\title{
Alonso de Cartagena y el debate sobre la caballería en la Castilla del Siglo XV*
}

\author{
Alonso de Cartagena and the debate on chivalry in \\ Fifteenth-Century Castile
}

\author{
LUIS FERnÁNDEZ GaLLARDO **
}

\begin{abstract}
RESUMEN
La amplia y variada reflexión de Alonso de Cartagena (1385-1456) sobre la caballería tiene un doble fundamento: aguda conciencia de las obligaciones estamentales y profundo sentido ético. Concibe la caballería como «officium»,

en su sentido ciceroniano, antes que como «ordo». Virtud esencial es la fortaleza de ánimo, que se manifiesta en la defensa de la fe, el servicio del rey y el bien común. El ideal caballeresco de

Cartagena corresponde a la figura de los «vasallos del rey». La integración en las estructuras estatales modificó el «ethos» individual, primando la prudencia, que se adquiere mediante el estudio y constituye un saber al que se aplican los «studia humanitatis», lo que no autoriza a definirlo como «humanismo caballeresco».
\end{abstract}

\section{PALABRAS CLAVE}

Alonso de Cartagena, Castilla, siglo XV, caballería, ideas políticas, humanismo.

\section{ABSTRACT}

The scope and diversity found in Alonso de Cartagena's (1385-1456) thoughts on chivalry are based on two guiding principles: An acute consciousness of one's social obligations and a profound sense of ethics. He conceives knighthood as an officium, in a Ciceronian sense, more than as an ordo. One of the essential virtues of chivalry is strength of the will which is manifested in the defence of the faith, service to the king and furthering the common good. The chivalric ideal expounded by Cartagena corresponds to the notion of «the king's vassals». Integration into the state structures modified the individual ethos, whereby prudence, acquired through study, is a form of knowledge fomented in the studia humanitatis, although it should not be misconstrued as «chivalric humanism».

\section{KEY WORDS}

Alonso de Cartagena, Castile, fifteenth century, chivalry, political ideas, humanism.

En el panorama intelectual y literario de Castilla en la primera mitad del siglo XV, Alonso de Cartagena es una de las personalidades más destacadas e

* Fecha de recepción del trabajo: 2012-5-10. Fecha de aceptación del trabajo: 2012-11-30.

** UNED (C.A. Albacete). C.e.: Ifernandez@albacete.uned.es 
influyentes. Ni escribió obra de ficción alguna, ni cultivó tampoco la lírica, en cuya veta moral y sentenciosa, que constituye una de las manifestaciones más características de la poesía castellana del siglo $\mathrm{XV}$, hubiera seguramente descollado. Ciertamente, se consideraba ante todo un jurista, hombre de leyes al servicio de la institución monárquica. Si cabe identificar el perfil de los juristas españoles que traza en el opúsculo polémico contra Bruni con la imagen que Cartagena tenía de sí mismo, se colige una esencial vocación curialesca. Al vindicar la ciencia jurídica hispana frente a la italiana, justifica la escasez de la producción escrita de los hombres de leyes españoles apelando a su entrega urgente al servicio de la curia, mientras que los italianos se ven impelidos a la escritura; mas no por ello dejan de exhibir un agudo ingenio los españoles en la discusión de las obras ajenas. Cuando don Alonso escribió sus Declamationes tenía cerca de cincuenta años y su obra escrita se limitaba a sus traducciones de Cicerón y Séneca y al Memoriale virtutum, un compendio de la Ética de Aristóteles profusamente apostillada. Su vocación literaria fue algo tardía: sólo a los treinta y siete años, en 1422, produjo su primera obra, la traducción de De senectute de Cicerón. Pero es más, no la escribió motu proprio, sino a instancias de su compañero de embajada, Juan Alfonso de Zamora, quien le había pedido insistentemente la versión castellana de algún texto de la Antigüedad.

Su justificación, desarrollada con detalle en el prólogo, define con precisión el lugar asignado a la actividad literaria dentro de su horizonte vital. La labor traductora se desarrolló en los espacios de ocio que dejaban las negociaciones diplomáticas: «las oras que sobravan del tiempo que sabedes»². El tiempo «que sabe» Juan Alfonso de Zamora es obviamente el tiempo dedicado a la labor diplomática. Ambos habían sido enviados a la corte lusa para negociar el acuerdo de la paz definitiva entre ambos reinos, en el marco del nuevo diseño de política exterior promovido por Álvaro de Luna ${ }^{3}$. Lo cierto es que tales tratos se prolongaron considerablemente, debido a la dificultad de llegar a un acuerdo en la delicada cuestión de la restitución de fortalezas y la compensación de los daños de guerra ${ }^{4}$. El ritmo parsimonioso de la negociación diplomática generaría amplios intervalos de ocio

Este trabajo forma parte del Proyecto de Investigación financiado por la Secretaría de Estado de Investigación (Ministerio de Economía y Competitividad) no HAR2010-16762, titulado: «Practicas de consenso y de pacto e instrumentos de representación en la cultura política castellana (siglos XIII al XV)», dirigido por el Prof. José Manuel Nieto Soria, de la Universidad Complutense de Madrid.

1 Alonso de Cartagena, Declamationes, apud Tomás González Rolán, Antonio Moreno Hernández, Pilar Saquero Suárez-Somonte, Humanismo y teoría de la traducción en España e Italia en la primera mitad del siglo XV, Madrid, Ediciones Clásicas, 2000, p. 196. La erudición jurídica, unida a la incoercible vocación por las letras que revela Cartagena, encaja en el perfil del iurisconsultus perfectus, caracterizado como «an encyclopedic scholar» [Donald R. Kelley, «Jurisconsultus perfectus. The Lawyer as Renaissance Man», Journal of the Warburg and Courtauld Institute, 51 (1988), pp. 89].

2 Alonso de Cartagena (trad.), De senectute, apud María Morrás (ed.), Alfonso de Cartagena, Libros de Tulio: De Senectute, De los ofiçios, Alcalá de Henares, Universidad del Alcalá de Henares, 1996, p. 157.

${ }^{3}$ Luis Suárez Fernández, «Aragón en la política de don Álvaro de Luna», R.A.B.M., LIX (1953), pp. 118-120.

4 Luis Fernández Gallardo, Alonso de Cartagena (1385-1456). Una biografía política en la Castilla del siglo XV, Valladolid, Junta de Castilla y León, 2002, p. 121. 
que propiciarían la dedicación a las letras. Ahora bien, don Alonso evoca su primera producción literaria como actividad ocasional. Destaca que llevó a cabo la traducción con poco esfuerzo, pues él dictaba y Juan Alfonso de Zamora escribía: como si quisiera limitar su quehacer en tal empresa ${ }^{5}$. Por otra parte, las elipsis y sobreentendidos del prólogo, la apelación a una situación sólo compartida por el autor y el comitente-escriba, circunscriben dicha pieza a un solo destinatario, sin contemplar una recepción ulterior más amplia. Cartagena no revela, por tanto, conciencia alguna de crear un texto dirigido a un público lector, sino que simplemente se limita a facilitar a su compañero de embajada el acceso a la lectura de los autores antiguos.

Sólo la insistencia de magnates amigos que deseaban beneficiarse del saber enciclopédico del docto prelado y el requerimiento de príncipes cultos lograrían que cuajara una vocación por la escritura que se mantendría activa hasta sus últimos días ${ }^{6}$. De hecho, toda su obra, excepto la Genealogía de los reyes de España, conocida como Anacephaleosis, fue escrita como resultado de una petición. Los temas tratados le venían impuestos de este modo por los intereses de los peticionarios. Y no sólo los temas. Aspectos esenciales como la elección de la lengua (latín o castellano) y de las formas del discurso estaban condicionados por las circunstancias en que las diferentes obras se gestaron. Sin embargo, ello no obsta el que, a pesar de tales condicionamientos, se manifieste un pensamiento vigoroso y original. Cabría decir que Alonso de Cartagena contribuyó de un modo determinante a modelar la ideología de la nobleza ilustrada castellana del siglo XV, aquella que aspiraba a redefinir los valores caballerescos sobre la base de los referentes de la cultura letrada, entre los cuales la Antigüedad constituye un espacio privilegiado?

Ahora bien, aun cuando la poderosa inteligencia de don Alonso tenía una gran capacidad para la sistematización, lo cual se pone de manifiesto en el extraordinario rigor formal de sus obras, su pensamiento se ofrece disperso, fragmentado en

\footnotetext{
${ }^{5}$ De senetute, p. 157.

${ }^{6}$ Y se manifiesta vigorosa en la aspiración a la fama literaria, que se revela en tensión con la aguda conciencia de sus obligaciones cívicas: «... si esperamos a que la fortuna nos dé tranquilidat e quiete, e en tanto que dura el tiempo turbado tenemos la péñola queda ¿non temeremos con grand razón que por ventura pase nuestra vida ocçiosa, syn dexar de sí escriptura durable?» [Alonso de Cartagena, Qüestión, ed. A. Gómez Moreno, El Crotalón, 2 (1985), p. 350]. «Dejar de sí escritura perdurable»: he ahí en cifra el ideal que anima el quehacer literario del Cuatrocientos castellano. Véase el profundo comentario de Juan Marichal, «El proceso articulador del siglo XV: de Cartagena a Pulgar», Teoría e historia del ensayismo hispánico, Madrid, Alianza Editorial, 1984, pp. 22-26.

7 Destaca el nuevo ideal caballeresco como resultado de la conjunción de las armas y las letras María Elvira Roca Barea, Tratado militar de Frontino. Humanismo y caballería en el cuatrocientos castellano. Traducción del siglo XV, Madrid, CSIC, 2010, pp. 62-75. Para la difusión de las ideas de Cartagena sobre la caballería, constituye un indicio significativo la presencia del Doctrinal de los caballeros en las bibliotecas de la época, estudiada por Noel Fallows, "Chivalric manuals in medieval Spain: the Doctrinal de los caualleros (c. 1444) of Alonso de Cartagena", Journal of Medieval and Rensaissance Studies, 24 (1994), pp. 74-77. Concluye que poseyeron esta obra nobles y juristas, que la utilizarían como obra de referencia (p. 77).
} 
el desarrollo parcial de los temas, de manera que incluso aquellos más frecuentemente tratados no llegan a constituir propiamente un sistema. Mas ello no obsta el que posea una coherencia, más allá de aparentes contradicciones, que no obedecen sino a las circunstancias específicas en que cada obra se gestó, al énfasis que determinados aspectos requerían en el contexto concreto en que se trataban Como un hilo que enhebra el pensamiento de Cartagena, una profunda inspiración ética atraviesa el tratamiento de los temas a los que se aplican sus cogitaciones. Ese fondo ético es quizás el elemento que más poderosamente garantiza la coherencia de su pensamiento.

Era natural, por tanto, que le fueran planteadas al docto prelado burgalés cuestiones diversas atingentes a la nobleza y a la caballería. Los nobles ilustrados castellanos se esforzaban entonces por redefinir su identidad estamental, su función social. En los autores antiguos entreveían la certeza que les confirmaría en un orden social que estaba experimentando las transformaciones derivadas del proceso de formación del estado moderno. El fortalecimiento de la monarquía, que manifestaba unas acusadas tendencias autocráticas ${ }^{8}$, supuso una modificación en las relaciones de la nobleza con la corona, que afectaba, asimismo, a su papel social $^{9}$, De ahí que la caballería sea una de los temas principales de la obra de Alonso de Cartagena. $Y$ así fue percibido en las generaciones siguientes, de que es elocuente testimonio Juan de Lucena, quien destacaría la contribución del obispo de Burgos al discurso caballeresco ${ }^{10}$.

Pero, a su vez, cabe constatar la fascinación que éste sentía por la milicia y la caballería. Testimonio sumamente elocuente al respecto es la atención que presta a las máximas caballerescas: es capaz de recordarlas incluso en el tenor literal de las lenguas en que se formularon, como el francés y el alemán ${ }^{11}$. No en vano, ta-

8 Proceso que generó una acusada conflictividad. Se ha definido precisamente el período comprendido entre 1400 y 1480 como de «expansión absolutista» [José Manuel Nieto Soria, «La monarquía como conflicto de legitimidades», La monarquía como conflicto en la Corona castellanoleonesa (c. 1230-1504), dir. J. M. Nieto Soria, Madrid, Sílex, 2006, pp. 53-68].

9 María del Pilar Carceller Cerviño, «Nobleza cortesana, caballería y cultura. La casa ducal de Alburquerque», Titulos, grandes del reino y grandeza en la sociedad política. Fundamentos en la Castilla medieval, dir. Ma C. Quintanilla Raso, Madrid, Sílex, 2006, pp. 218-219. Por otra parte, no hay que perder de vista que la ideología y los ideales de la caballería surgieron en el marco cortesano (Aldo Scaglione, Knights at Court. Courtliness, Chivalry, \& Courtesy from Ottonian Germany to the Italian Renaissance, Berkeley-Los Angeles-Oxford, University of California Press, 1991, pp. 17-44).

10 «Tú de cauallería, de re pública, de fe cristiana escreuiste vulgar, y las obras famosas del moral Séneca nuestro vulgarizaste.» (Juan de Lucena, ed. A. Paz y Melia, Opúsculos literarios de los siglos XIV á XV, Madrid, Sociedad Española de Bibliófilos, 1892, p. 113).

11 Máxima francesa: «...vnde fertur in Gallia e(ss)e prouerbium vulgare: "Seppe bonus torneator est timidus (et) coardus bellator"’” (Alonso de Cartagena, Memoriale virtutum, BNE, ms. 9178, fol. 18 ํo). Repite dicho proverbio en castellano, ya sin indicación de su origen francés, unos veinte años más tarde: «E proverbio antiguo dizen que es que "a las vezes el buen torneador es temeroso e cobarde batallador"» [Alonso de Cartagena, Doctrinal de los de los cavalleros, ed. José Mª Liste, Santiago de Compostela, Universidade de Santiago de Compostela, 1994, p. 192. Hay edición más reciente de esta obra: Noel Fallows (ed.), Alonso de Cartagena, Tratados militares, Madrid, Ministerio de Defensa, 2006, pp. 55-444]. Máxima alemana: «... yo vy al Rey de los romanos, Alberto, quando yua a la guerra polónica a algunos gentiles omes armar caualleros, e fazíalos assý: estando delanye dél omillados, daua a cada vno tres golpes con vna 
les fórmulas condensan aspectos esenciales del mundo caballeresco, como el ceremonial de investidura o valores centrales del ethos caballeresco. Cartagena se revela como fino observador del mundo de los caballeros. Igualmente significativa es la preciosa noticia que él mismo ofrecería de sus años de estudiante: la defensa de una tesis relativa al estamento caballeresco en una disputatio de quolibet ${ }^{12}$. Gracias a esta confidencia se documenta cómo el debate sobre la caballería se desarrollaba asimismo en el ámbito universitario, enriqueciéndose de este modo con el aporte de instrumentos intelectuales propios de la cultura letrada, muy especialmente el uso de argumentos extraídos del Derecho Común. Así, pues, don Alonso, por su condición de erudito jurista, reunía las condiciones idóneas para la construcción de una ideología caballeresca de nuevo cuño, basada tanto en el modelo idealizado de la Antigüedad como en la ciencia jurídica escolástica.

\section{LA MILITIA COMO METÁFORA DE LA VOCACIÓN DE SERVICIO.}

\section{Militia armata y militia inermis.}

Independientemente del atractivo que pudiera sentir Cartagena por el mundo de las armas, un poderoso incentivo de su interés hubo de ser la intuición de que el concepto de caballería podía constituir un medio idóneo para definir y afirmar la identidad y función social de los letrados en el marco de una monarquía que acentuaba sus tendencias autocráticas. El testimonio más significativo al respecto se halla en el discurso forense que pronunció en Aviñón, camino de Basilea (1434). El exordio, cuidadosamente elaborado, traza un paralelo entre caballeros y letrados, a quienes urge un mismo afán, que viene a identificarse con el concepto de militia:

In me(n)tem venit, o doctores egregii ceteriq(ue) scolastici viri, solere eos, qui armate milicie operam dant, cum $\mathrm{p}$ (er)egre profecti ad extraneorum principum curias declinant et aliquos armorum labores experiri, ut qualis professio sua sit opis exercicium demostret et noua $(m)$ sorte artis militaris doctrinam ab ip(s)is nouis quos uident discant. Quod et milicie inermis viros equi sepe comp(er)tum est. $\mathrm{Na}(\mathrm{m}) \mathrm{cum}$ solemnia exterarum nacionum studia peragrant, cum uiris studiosis plerumq(ue) con-

\footnotetext{
espada desnuda de lo llano en las espaldas, diziendo a cada golpe en su lengua: "pesçer ricter denlrenet", que quiere dezir "mejor es ser cauallero que escudero." E con esto eran armados sin otro juramento nin promisión.» (Qüestión, p. 360). Véase el erudito análisis de esta última en Carlos Clavería, «Una fórmula alemana en Alfonso de Cartagena», Revista de Filología Española, XXVI (1942), pp. 307-311.

12 «E miémbraseme seyendo moço, ante que del estudio saliese, en vn acto escolástico auer puesto tal conclusión: que los vasallos del rey nuestro señor, avnque caballeros non sean, de los priuillejos militares deuen gozar; e avnque en juyzio non la siguiría, porque algunas leyes del regno e la costunbre le paresçen contradezir, pero en disputaçión escolástica, donde el derecho común e la razón dél solamente por actoridad alegar se podiese, por ventura se defendería.» (Qüestión, p. 362).
} 
ferre solent ut quos excellentes rep(er)erint debita reuerencia colant et de purissimis sapiencie fo(n)tibus bonarum doctrinarum purissimam aqua $(m)$ bibant ${ }^{13}$.

Sobre el término militia hace pivotar Cartagena su argumentación para fundamentar las aspiraciones sociales de los letrados universitarios; constituye el puente que une dos espacios sociales diferentes, tanto en sus formas de vida como en lo relativo a su función social. Militia armata y militia inermis: don Alonso reproduce la antítesis análoga que figura en la Institutio Traiani del Pseudo-Plutarco. El opúsculo educativo dirigido al emperador Trajano apareció por vez primera en el Policraticus de Juan de Salisbury (1115-1180), fruto granado del denominado renacimiento del siglo XII al servicio de una concepción política organicista ${ }^{14}$. No necesariamente hubo de tomar Cartagena la antítesis en cuestión del Policraticus, pues no lo cita en toda su dilatada obra; a su vez, hay que tener en cuenta que el primero de los dieciséis fragmentos de que consta, precisamente el que contiene la imagen en cuestión, circuló independientemente ${ }^{15}$. Sea cual fuere la vía por la que accedió a la Institutio - o a su primer fragmento-, es el caso que don Alonso desarrolla el planteamiento de ésta, transfiriendo los términos de la antítesis armata-inermis de las «manos» a la militia.

El término militia añadía a su significado concreto (conjunto de los milites) la correspondiente abstracción: forma de vida y valores de los milites. Debido a la evolución semántica de este último vocablo, los valores y forma de vida del miles en el siglo XV no eran sino los del caballero. Sin embargo, el término conservaba

\footnotetext{
${ }^{13}$ Alonso de Cartagena, Tractatus super legem Gallus, Archivo de la Catedral de Burgos, cód. 11, fol. 1 ro a. Hay edición moderna y traducción de este texto (Rafael Sánchez Domingo, El Derecho Común en Castilla. Comentario a la Lex Gallus de Alonso de Cartagena, Burgos, Santos, S.L., 2002, pp. 284-388). Se cita por el manuscrito para adoptar otra puntuación.

14 «Manus itaque reipublicae aut armata est, aut inermis. Armata quidem quae castrensem et cruentam exercet militiam; inermis quae iusticiam expedit et ab armis feriando iuris militiae servit.» (Institutio Traiani, IX, apud Hans Kloft, Maximilian Kerner, Die Institutio Traiani. Ein pseudo-plutarchischer Text im Mittelalter. Text -Kommentar - Zeitgenössischer Hintergrund, Stuttgart, B. G. Teubner, 1992, p. 24). Cfr. Juan de Salisbury, Polycraticus, ed. J.-P. Migne, Patrologia Latina [= PL], t. CXCIX, París, In via d'Amboise, 1855, col. 589. Para la difusión de la Institutio véase Marianne Pade, The Reception of Plutarch's Lives in Fifteenth-Century Italy, Copenhague, Museum Tusculanum Press, 2005, vol. I, pp. 62-66; para el ámbito hispano, Jorge Bergua Cavero, Estudios sobre la tradición de Plutarco en España (siglos XIII-XVII), Zaragoza, Universidad de Zaragoza, 1995, pp. 68-94, que ofrece un riguroso análisis del status questionis; Ana Huélamo San José, «La Epístola de Plutarco a Trajano: modelos de transmisión», Actas del XIII Congreso de la AHLM, Valladolid, Universidad de Valladolid, 2010, t. II, pp. 1013-1025 (analiza su recepción en la Estoria de España y en el Communiloquium de Juan de Gales y su versión castellana, el Libro del gobernador o Suma de collaciones). Apunta la dependencia directa de la Estoria de España respecto del Policraticus o de la propia Institutio Traiani Miguel Ángel Ladero Quesada, «El emperador Trajano como modelo de príncipes en la Edad Media (El príncipe en "Policraticus")», Anuario de Estudios Medievales, 29 (1999), p. 506, hipótesis que abre una nueva perspectiva en la recepción del Policraticus y la Institutio Traiani en España, al adelantar considerablemente su conocimiento directo, en lugar de las mediatizaciones de Vicente de Beauvais o Juan de Gales. Ciertamente, la difusión en España de la obra de Salisbury fue mucho más limitada que en Inglaterra (es obvio), Francia e Italia: sólo figura un manuscrito español, y éste del siglo XV, del Entheticus, en el amplio panorama que al respecto traza Ammon Linder, «The Knowledge of John of Salisbury in the Late Middle Ages», Studi Medievali, XVIII.2 (1977), pp. 317-366 (cita del manuscrito en p. 359).

15 Marianne Pade, The Reception, vol. I, p. 63.
} 
toda una carga semántica, heredada del latín cristiano en virtud de las vicisitudes que experimentó el concepto militia en la cosmovisión cristiana, que no podía dejar de estar presente para un eclesiástico de la erudición de Cartagena. Desde la máxima de Job que condensa una visión de la vida en permanente afán — «Militia est vita hominis super terram.» $(I o b, 7,1)-^{16}$, hasta el concepto de militia Christi ${ }^{17}$, desde la Biblia hasta los Padres de la Iglesia, un amplio arco de ideas gravitaba sobre el término militia, ofreciendo la posibilidad de su adaptación a contextos diversos y, sobre todo, del establecimiento de diversas combinaciones.

Militia armata: el pleonasmo toleraba la acepción restricta del término, la más usual en el siglo XV, esto es, caballería. Mas el oxímoron militia inermis activaba la posibilidad del significado traslaticio y más amplio, que permitía, de este modo, su adaptación a diversos propósitos. La idea de establecer una antítesis en el seno de la caballería arranca de Bernardo de Claraval, al formular el nuevo ideal caballeresco que constituiría uno de los pilares de la propaganda de la segunda cruzada. En el opúsculo De laude novae militiae, al confrontar la nueva caballería a aquella que pretendía renovar, anquilosada en la perversión, formula la oposición entre la militia Dei y la militia saeculi ${ }^{18}$. Alonso de Cartagena desplaza el eje de la oposición de la moral a la función social. Ya no se trataba de sustituir una moral degradada y caduca, sino de delimitar los ámbitos de acción de los estamentos sociales. Para ello proyecta la oposición funcional de la Institutio Traiani sobre una noción de la caballería que viene a identificarse con lucha y esfuerzo. El sentido amplio del término permitía asimilar la labor de los letrados a la de los caballeros: ambos se afanan y esfuerzan en el servicio a la corona, unos con las armas, otros con la palabra adiestrada en la práctica forense ${ }^{19}$. La moral combativa de los caballeros, de los milites, se aplicaba, de este modo, a la vindicación de la función social de los letrados. El servicio que prestaban a la corona podía considerarse de índole análoga al de los caballeros ${ }^{20}$.

Ahora bien, el paralelo que establece don Alonso entre caballeros y letrados parece centrarse en un aspecto más bien secundario: ambos colectivos empren-

16 Y que sería glosado por el propio Cartagena para justificar el sentido amplio del término caballería (Qüestión, p. 354).

17 Que arranca de la referencia paulina al «bonus miles Christi» (Ad Timotheum, 2, 2, 3). Análisis exhaustivo de los textos bíblicos y patrísticos en que se cimenta la idea de «milicia de Cristo» en Adolf von Harnack, Militia Christi. Die christliche Religion und der Soldatenstand in den ersten drei Jahrhunderten, Tubinga, J. C. B. Mohr, 1905.

18 San Bernardo de Claraval, De laude novae militiae, ed. J.-P. Migne, Patrologia Latina [= PL], t. CLXXXII, París, In via d'Amboise, 1854, col. 926.

19 Es de notar que Egidio Romano ((1243-1316) ya había establecido la analogía entre caballeros y letrados en el marco del servicio al bien común: «Nam milicia uidetur esse quaedam prude(n)tia operis bellici ordinata ad com $(\mathrm{m})$ une bonu(m), uidetur se habere milites in opere bellico sicut magistri et doctores i(n) scientiis aliis.» (De regimine principum, III, 3, 1, Venecia, Simon Breuilaqua, 1498, sig. $\mathrm{u}$ iii $\mathrm{v}^{\mathrm{o}}$ ).

20 Matiza la oposición entre caballeros y letrados en la obra de Cartagena Luis X. Morera, «An Inherent Rivalry between Letrados and Caballeros? Alonso de Cartagena, the Knightly Estate and a Historical Problem», Mediterranean Studies, 16 (2007), pp. 67-93. 
den largos viajes movidos por un afán de aprender los saberes propios del oficio anejo a su función estamental. Ciertamente, la apelación a la índole viajera de los letrados vendría impuesta por la presencia del propio Cartagena en el estudio aviñonense, que se justifica por la vocación discente inherente al gremio universitario. Sin embargo, el afán por apurar la analogía entre caballeros y letrados iba a conducir a destacar un rasgo novedoso de la caballería castellana del Cuatrocientos, su aspiración a constituirse en un cuerpo doctrinal, esto es, en un saber formalizado, que se incardinaría en el ámbito de las preocupaciones intelectuales propias del humanismo ${ }^{21}$. Así, más allá de lo meramente anecdótico, la semejanza entre los afanes viajeros de ambos estamentos apuntaba en última instancia a destacar que el oficio de caballeros y letrados, el desempeño de su función en el orden estamental, requería una instrucción, el aprendizaje de un saber libresco. El servicio que se presta a la corona con las armas exige, por tanto, una cualificación que se obtiene por vía análoga a la de los letrados, a través del estudio.

\section{Letrados y clérigos y su integración en la órbita caballeresca.}

La analogía o comunidad funcional de los trabajos de caballeros y letrados adquiriría un desarrollo más amplio en la respuesta que dio Alonso de Cartagena a la cuestión que le planteó el Marqués de Santillana sobre el juramento que los antiguos romanos «fazían al tiempo que avían de yr en las huestes e exerçitos» "22. Conviene precisar que más que una respuesta propiamente dicha a la cuestión planteada, se trata de un breve compendio o tratado sobre la caballería, aunque el autor no pierde de vista que el asunto más destacado es el juramento de los caballeros, conforme a la petición de Santillana. Y es que Cartagena no había leído el opúsculo de Leonardo Bruni, De militia ${ }^{23}$, que motiva la pregunta de don Íñigo, por lo que no puede responder con la exactitud deseada. De ahí que decida disertar libremente sobre los caballeros y los juramentos que prestan, aun cuando conocía la fórmula de juramento castrense de que informa Vegecio ${ }^{24}$.

21 De ahí que se haya postulado al respecto para Castilla un humanismo caballeresco, análogo al que se desarrolló en Italia [Jesús D. Rodríguez de Velasco, «De Prudentia, Scientia et Militia. Las condiciones de un humanismo caballeresco», Atalaya, 7 (1996), pp. 117-132]. Desde un planteamiento diferente se había propuesto asimismo para el ámbito español un «humanismo de las armas» (José Antonio Maravall, Utopía y contrautopía en el Quijote, Santiago de Compostela, Pico Sacro, 1976 pp. 111-148).

22 Íñigo López de Mendoza, Marqués de Santillana, Questión fecha a don Alonso de Cartagena, Obras completas, ed. Ángel Gómez Moreno, Maximilian P. A. M. Kerkhof, Barcelona, Planeta, 1988, p. 415. La respuesta está fechada el 17 de marzo de 1444.

${ }^{23}$ Gordon Griffiths, James Hankins, David Thompson, The Humanism of Leonardo Bruni, Nueva York, Binghamton, 1987, pp. 107-111 (versión inglesa del tratado en pp. 127-145). La traducción castellana que leyó Santillana ha sido editada en Carlos Heusch, La caballería castellana en la baja edad media, Montpellier, ETILAL, 2000, pp. 107-123.

${ }^{24}$ Qüestión, pp. 357-358. Cfr. Vegecio, Epitoma rei militaris, II, 5. Aun cuando podía haberla conocido a través de la Institutio Traiani (cfr. Juan de Salisbury, Policraticus, VI, 7, p. 440), el texto de la Qüestión se mantiene más cerca del original del tratadista romano. 
El punto de partida de su reflexión es un riguroso análisis léxico del término miles, para lo cual remonta a su etimología, pues constata el uso erróneo que de él se hace, tanto «en los libros commo en el uso comun de nuestro fablar» (Qüestión, p. 353). La recuperación del genuino significado que el vocablo tenía en latín, más amplio que el que lo limitaba al caballero, permitiría formular un concepto más comprensivo: «omne deputado a actos de guerra e defensor de la republica, por aquella espeçie de defensión que por via de armas se faze» (Qüestión, p. 353). Se observa la tensión entre la terminología tradicional, la apelación al defensor, correspondiente a la representación trifuncional del orden social medieval, y el nuevo concepto de república ${ }^{25}$, que permitía reformular las nociones de «tierra» y «pueblo» en el marco de la gestación del estado moderno. Cartagena enfatiza la función, defensa de la república, con respecto a la cual, la forma (mediante las armas) constituiría una suerte de especificación. Ahora bien, dicha defensa no tiene por qué realizarse exclusivamente con las armas: se deja, por tanto, expedita la vía para incluir otro tipo de «defensores», como clérigos y letrados, cuyos oficios cabe asimilar a la defensa de la república ${ }^{26}$. A la asimilación de los

${ }_{25}$ Aunque el neologismo contaba con más de medio siglo de circulación en castellano —a tenor de Ios datos ofrecidos en CORDE. Corpus Diacrónico del Español <http://corpus.rae.es/cordenet.html> s. v. república. Muy significativamente, el traductor del opúsculo de Bruni De militia sentía el término como ajeno al castellano, por lo que hubo de introducir un inciso aclaratorio para definirlo: «... re publica —que quiere dezir de lo que tañe al príncipe o a todo el pueblo-...» (De la caballería, p. 113). En cambio, lo traduce literalmente por «cosa pública» (p. 110). De especial interés es su uso por parte de los letrados que redactaron el cuaderno de las Cortes celebradas en 1433 en Madrid: «... para bien e pro comun e buen rregimiento e gouernaçion dela vuestra justicia et dela rrepublica delos vuestros regnos...» (Cortes de los antiguos reinos de León y Castilla, ed. Real Academia de la Historia, t. III, Madrid, Imprenta de M. Rivadeneyra, 1866, p. 185)

26 «... otros algunos que por otras vías la defienden, suelen las escripturas llamar caualleros, commo los saçerdotes que orando delante del trono diuino e los letrados allegando delante los tribunales humanos trabajan por escapar a los que son en peligro.» (Qüestión, p. 353). El paralelo con el oficio de los clérigos cuajaría en la formulación de una caballería virtuosa o eclesiástica. Al franciscano Juan de Gales († 1285) se debe una sistematización de la milicia, en la que distingue cuatro tipos, siendo el cuarto la clerical: «Et est militia virtuosa siue ecclesiastica $q(u a m)$ militant $p(r e)$ lati Ecclesie (et) predicatores illius (et) contra heresim (et) contra erroru(m) adinuentores.» (Communiloquium, I, 9, 8, Summa regimine vite humane seu Margarita doctorum, Venecia, Georgius de Arriuabenis Mantuanus, 1498, fol. 63 vo b). La doctrina de Juan de Gales sobre la caballería sería traducida por Juan García de Castrojeriz, Glosa castellana al «Regimiento de príncipes» de Egidio Romano, III, iii, cap. 14, ed. J. Beneyto, Madrid, Instituto de Estudios Políticos, 1947, p. 367, quien identifica la milicia «virtuosa o eclesiástica» con el miles Christi de san Pablo. De hecho, en la misma Qüestión se hace referencia a la «milicia eclesiástica» (Qüestión, p. 361). Sumamente significativo al respecto es que el Decretum de Graciano aduzca la autoridad de san Ambrosio para mostrar la esencial heterogeneidad del servicio de ambas milicias, la índole espiritual de la lucha de los clérigos: «Non pila quaerunt ferrea, non arma Christi milites. Coactus repugnari non novi: sed dolor, fletus, orationes, lacrymae fuerunt mihi arma adversus milites.» (Decretum, C. 28, q. 8, c. 3, ed. J.-P. Migne, PL, t. CLXXXVII, París, Rue Petit Montrouge, 1861, cols. 1246-1247). Y sin embargo, historiadores y publicistas de las órdenes militares se esforzarían en destacar la homogeneidad de la lucha corporal y espiritual por vía alegórica. Sumamente ilustrativo es el excurso que el historiador de la Orden Teutónica Peter von Dusburg incluye en su crónica, asimilando la panoplia caballeresca (escudo, espada, lanza, rodela, loriga, arco y carcaj, saeta, honda, bastón y casco) a funciones espirituales (Cronica terre Prussie, Scriptores Rerum Prussicarum. Die Geschichtsquellen der preussischen Vorzeit bis zum Untergange der Ordensherrschaft, ed. Th. Hirsch, M. Töppen, E. Strehlke, t. I, Leipzig, Verlag von S. Hirzel, 1861, pp. 40-44). 
letrados, expertos en Derecho, a la caballería, ya propuesta en la Institutio Trajani, cuya antítesis es nuevamente citada ${ }^{27}$, se añade la de los clérigos.

Para ello había que tensar al máximo el significado de «defensa», que no se limitaba a la respuesta a la amenaza física, sino que venía Cartagena a identificar con el mantenimiento del orden social. Aunque no pierde de vista que se trataba de un sentido traslaticio (Qüestión, pp. 353-354), dicha asimilación constituía un poderoso argumento para la vindicación de la función social de los letrados. Pero, de la misma manera que el mundo de los letrados se veía atraído a la órbita de la caballería, ésta, a su vez, experimentaba la correspondiente atracción hacia los valores propios de aquél. Y no sólo en lo que respecta al estudio, a la proclamación de la necesidad de adquirir un saber formalizado, libresco; asimismo la caballería asumiría la idea de servicio, no tanto referido a la república de una manera genérica y abstracta, sino incardinado en el entramado institucional de la nueva monarquía que se gesta en el proceso de formación del estado moderno. De este modo, se desplazaba el énfasis en la concepción de la caballería desde el privilegio anejo a la dignidad hacia la función social, unas obligaciones de índole análoga a las de letrados y clérigos, esto es, mantener el orden social, contribuir al bien de la república.

\section{Deslindes semánticos.}

Una cosa era la estrategia argumentativa mediante la cual se aprovechaba la ocasión de disertar sobre la caballería para vindicar el status de los letrados a través de un concepto amplio de ésta y otra el análisis riguroso de la figura del caballero $^{28}$. Alonso de Cartagena no pierde de vista nunca el significado restricto del término, lo que él denomina la «propia e estrecha significación» (Qüestión, pp. 353, 355). Así, tras discurrir ampliamente sobre los conceptos de caballería y caballero, aclara el significado propio. Caballero, "sin adiçión de alguna calidad [...] toda vía se entenderá el cauallero con armas» (Qüestión, pp. 353-354). Pero cabía afinar aún más en el análisis semántico.

En efecto, don Alonso parte en su análisis del término latino miles, «que por cauallero solemos romançar» (Qüestión, p. 355). Se acoge al latín como si sintiera que pisaba terreno más firme en la disquisición lexicográfica ${ }^{29}$. Ciertamente, el término latino permitía, por vía etimológica, remontarse al origen y principio de la

\footnotetext{
27 «Pero estos llamamos los cavalleros de la cavalleria desarmada e los otros de la con armas.» (Qüestión, p. 353).

${ }_{28}$ Ese prurito analítico por clarificar el origen y significado del término «caballero», que anima la tratadística castellana cuatrocentista, se ha atribuido a la profusión de grupos de caballeros [Mª Isabe Pérez de Tudela Velasco, «La dignidad de la caballería en el horizonte intelectual del s. XV», En la España Medieval, V (1986), p. 814].

29 Se ha interpretado, por otra parte, la disquisición etimológica como forma de demostrar la autoridad del autor en la materia tratada (Noel Fallows, «Chivalric manuals», p. 67).
} 
caballería ${ }^{30}$, aunque, por otra parte, el uso de la etimología del vocablo latino había sido consagrado por las Partidas, la gran obra legislativa de Alfonso X el Sabio que contenía la doctrina más amplia acerca de la caballería hispana ${ }^{31}$. A su vez, no habría que descartar el que la exposición etimológica obedezca a que Bruni incluyó análogas consideraciones en su opúsculo al tratar del origen de la caballería $^{32}$. No deja de ser significativo el que el humanista florentino se extienda ampliamente en los dos primeros étimos, haciendo gala de sus conocimientos del griego, $y$, en cambio, despache rápidamente el consagrado en los repertorios léxicos más comunes, el que se refiere al cardinal mil (De la caballería, p. 111). Diríase que la detallada noticia que don Alonso ofrece de la etimología consagrada, con mención expresa de san Isidoro y tácita del Catholicon ${ }^{33}$, constituye una suerte de impugnación de la exposición del Aretino. Por su parte, los datos tomados de las Etymologiae ofrecían cumplida información sobre las raíces clásicas de la milicia, que se complementa con las Partidas y el Derecho Común, aducidas como refrendo de la autoridad isidoriana ${ }^{34}$.

Por otra parte, don Alonso se sentía compelido a utilizar en sus consideraciones el término latino, dado que la pregunta planteada se refería a los usos de la milicia romana. Mas, a diferencia del interés más propiamente «anticuario» que revela Santillana por los usos castrenses de la antigua Roma, el obispo de Burgos no pierde de vista la necesidad de aplicar el estudio del pasado a la realidad presente. De ahí que apele al deseo de «adaptar la manera antigua de escreuir algunt tanto a lo que oy en la fabla traemos» (Qüestión, p. 355). De esta manera, puede prescindir de usos léxicos inadecuados para el tema tratado y centrarse así en lo que en realidad le interesaba, definir el perfil preciso de la «cauallería solepne, que se da por orden e dignidat» (Qüestión, p. 355).

Por entre la maraña semántica se descubre el verdadero objeto que va a ocupar las cogitaciones de Cartagena. En vez del juramento de los antiguos caballeros romanos, va a tratar de la caballería actual, en la que destaca dos rasgos esenciales: el ritual de investidura, designado metonímicamente por su cualidad esencial, la solemnidad, y el honor, la fama. Ceremonial y preeminencia social. El obispo de Burgos capta con clarividencia uno de los componentes fundamentales de la caba-

\footnotetext{
30 Cartagena se muestra deudor en este punto de la añeja tradición que eleva la etimología a clave explicativa de la realidad nombrada y que, desde la Antigüedad, recorre el Medievo prolongándose en el humanismo (Ernst Robert Curtius, Literatura europea y Edad Media latina, México, FCE, 1955, t. II, pp. 692-699).

${ }^{31}$ Partida II, tít. XXI, ley II, Las siete Partidas del rey don Alfonso el Sabio, ed. Real Academia de la Historia, Madrid, 1807, t. II, p. 198.

32 Cfr. De la caballería, pp. 110-111.

33 Qüestión, p. 354. Ya quedó apuntado el recurso de Cartagena al Catholicon en la Qüestión en Luis Fernández Gallardo, Alonso de Cartagena, p. 378. ¿Acaso silencia el socorrido repertorio léxico porque había constatado su descrédito en los círculos humanistas que entonces frecuentaba?

${ }^{34}$ Qüestión, p. 354. Cfr. Partida II, tít. XXI, ley II, pp. 198-199 (sobre la etimología de miles); Graciano, Decretum, D. 1, c. 12, col. 32 (sobre el «derecho de los quirites»).
} 
Ilería: los ritos que formalizaban el acceso a la condición de caballero ${ }^{35}$. Es de notar cómo al socaire de las consideraciones sobre las ceremonias de investidura reitera la analogía entre caballeros y letrados, poseedores estos últimos asimismo de similar «solepnidad» para acceder al «grado de magesterio o doctoramiento» (Qüestión, p. 360$)^{36}$. La solemnidad se vincula al orden y a la dignidad, concebidas éstas como fundamento de ese ceremonial en virtud del cual se accedía a una nueva condición.

Orden y dignidad son términos que poseían un denso contenido dentro de una amplia tradición de reflexión política y social que arranca de la antigua Roma. El primero poseía originariamente doble significado: el más habitual, gradación dentro de una jerarquía, y ejercicio de la autoridad ${ }^{37}$. Este último se mantendría especialmente en el ámbito eclesiástico con carácter exclusivo. Su asociación a «dignidad» no carece de significado. En efecto, «dignidad» vendría a ser para el prelado burgalés el concepto clave para definir la preeminencia social de los caballeros. Dicho término desempeñó un importante papel en las luchas políticas de los últimos años de la República romana; en tal contexto designaba el buen nombre, la reputación ${ }^{38}$, esto es, el prestigio social. A Cicerón se debe una acabada formulación de la noción de dignitas, que vinculaba estrechamente con otro concepto nuclear en el pensamiento político occidental, auctoritas: «dignitas est alicuius honesta et cultu et honore et verecundia digna auctoritas» ${ }^{39}$. La importancia de la definición ciceroniana es decisiva para valorar el alcance del término en el pensamiento de Cartagena. En primer lugar, hay que tener presente que dicha definición aparece reproducida literalmente en el repertorio léxico al que don Alonso reconocía máxima autoridad ${ }^{40}$. En segundo, este tratado retórico fue traducido por don Alonso durante su estancia en la corte lusa, a instancias del príncipe don Duarte ${ }^{41}$.

35 De «realidad nuclear» lo califica Ma Concepción Quintanilla Raso, Nobleza y caballería en la Edad Media, Madrid, Arco/Libros, 1996, p. 53. Destaca el valor simbólico y su trascendencia política y social Jean Flori, Chevaliers et chevalerie au Moyen Âge, París, Hachette, 1998, pp. 219-233.

${ }^{36}$ Tal analogía venía a reflejar la aspiración de los letrados a integrarse en la nobleza (Jacques Verger, Les gens de savoir en Europe à la fin du Moyen Âge, París, PUF, 1998, pp. 211-217).

37 Análisis de la evolución semántica en Georges Duby, Los tres órdenes o lo imaginario del feudalismo, Barcelona, Argot, 1983, pp. 115-118.

38 J. P. V. D. Baldson, «Auctoritas, dignitas, otium», The Classical Quarterly, X (1960), pp. 44-46. Con precisión sería definida la dignidad por uno de los más destacados ideólogos de la caballería castellana: "calidad ayuntada a la persona, la qual le da alguna preeminencia» (Mosén Diego de Valera, Espejo de la verdadera nobleza, ed. M. Penna, B.A.E., CXVI, Madrid, Atlas, p. 98a).

39 De inventione, II, 166. Sobre el concepto de auctoritas en la experiencia romana véase Rafael Domingo, Auctoritas, Barcelona, Ariel, 1999, pp. 13-50. Hay que tener en cuenta que dignitas no tenía equivalente griego, por lo que se traducía por axioma, que en latín significa precisamente dignitas. No le debía de ser ajena a Cicerón esta circunstancia. Y sin embargo, en la literatura patrística se constata lo problemático de la atribución de dignitas a la militia, desde un planteamiento cristiano. Cfr.: «Posset in isto capitulo etiam de militia definitum videri, quae inter dignitatem et potestatem est.» (Tertuliano, De idolatria, XIX, ed. J.-P. Migne, PL, t. I, París, Apud Garnier Fratres, 1878, col. 767). Para las ideas de Tertuliano acerca de la militia véase Adolf von Harnack, Militia Christi, pp. 32-40.

$40 \mathrm{Su}$ autor completa el perfil semántico del término: «Ite $(\mathrm{m})$ dignitas decus, laus, nomen, gloria, summus honor.» (Johannes Balbus, Catholicon, s. v. dignitas, Mainz, Gutenberg?, 1460, fol. 139 rơ).

41 Para su situación en el contexto de las traducciones de Cicerón véase María Morrás (ed.), Alonso de Cartagena, pp. 19-20. 
Por tanto, la idea de «dignidad» que tenía el obispo de Burgos había de estar influida en un alto grado por la definición de Cicerón, consagrada por el Catholicon, cuyo autor, a su vez, la desarrolló destacando la noción de prestigio, fama, en definitiva: honor.

\section{LA CABALLERÍA: ENTRE ORDO Y OFFICIUM.}

Al hilo de las precisiones léxicas incluidas en la Qüestión aparece de nuevo el término «orden» para definir la caballería. Tras exponer las acepciones más amplias del término miles, Cartagena incluye la que considera «particular»: «cauallero armado por rey o por otro que armarle pueda [...] E estos tales se dizen tomar la orden de cauallería, la qual tiene sus reglas e obseruançia.» (Qüestión, p. 355). Orden posee en este contexto un sentido diferente al mencionado anteriormente. Viene a apuntar a corporación que se identifica por la asunción de unas normas determinadas y peculiares ${ }^{42}$. Al ser utilizado en singular, el término «orden» parece bascular hacia una noción estamental ${ }^{43}$. Don Alonso, no obstante, reserva el término «estado» para dicho concepto, cuyo sentido desarrolla con cierto pormenor ${ }^{44}$.

Ahora bien, el paralelo que establece en cuanto a rigor entre las reglas de la caballería y las de cartujos y franciscanos (Qüestión, p. 356) parece situar el término «orden» más bien en el horizonte plural de las órdenes de caballería. A su vez, diríase que la analogía fuese expresiva de que permanecía activa la restricción de la autoridad aneja al ordo al ámbito eclesiástico. El aquilatamiento de la vocación caballeresca, contemplada como una ascesis que tiene una acusada dimensión cívica, se lleva a cabo mediante la analogía con el estamento eclesiástico. La militia adquiría así una cierta dimensión sacral, sólo que limitada al mero símil religioso.

En cualquier caso, la «orden» a que alude Alonso de Cartagena no se puede identificar con estamento al que le corresponde una función social, esto es, con el

42 Como era el caso de las órdenes caballerescas, cuyo rasgo definitorio era la posesión de un cuerpo de estatutos (Maurice Keen, La caballería, Barcelona, Ariel, 1986, p. 240), esto es, las «reglas e obseruançia».

43 Para don Juan Manuel, sin embargo, «orden» y «estado», referidos a la caballería, son términos sinónimos: «Et otrosí porque d'esta orden et d’este estado son los reis et los grandes señores...» (Don Juan Manuel, Libro del caballero et del escudero, Obras completas, ed. Carlos Alvar-Sarah Finci, Madrid, Biblioteca Castro-Fundación José Antonio de Castro, 2007, p. 380).

44 De hecho, la justificación de la inclusión de disposiciones relativas a guerreros que no son caballeros en la recopilación de leyes sobre la caballería reposa sobre la noción funcional de estado social: «En todos los ayuntamientos de gentes cumple que aya diversos estados para que algún fruto se pueda fazer, ca — segund dizen los filósofos - non se podría poblar la cibdad si todos fuesen ricos, ca non abría quien labrase las heredades nin quien quisiese fazer algunas cosas que son necesarias para enderesçamiento de la república que son baxas e viles...» (Qüestión, pp. 49-50). 
de los "defensores» ${ }^{45}$, por la elemental razón de que los caballeros no son los únicos que se dedican al ejercicio de las armas: las dos acepciones del vocablo miles dejaban en evidencia que los caballeros, conforme a la «propia e estrecha significación», constituían en rigor un grupo dentro de los «deputados a guerrear» (Qüestión, p. 355). En la medida en que la caballería no monopolizaba la actividad guerrera, resultaba más adecuado definirla, en lo que respecta a su función social, como «oficio». Es más, de hecho, «orden» y «oficio» vienen converger en la caracterización restricta de los caballeros como grupo social que hace Cartagena ${ }^{46}$.

Precisamente Santillana, al mencionar el opúsculo de Bruni que motiva la cuestión que plantea a su amigo el obispo de Burgos, se refiere al «ofiçio de la caballería», como objeto de su interés (Questión, p. 414). El término "oficio» debía poseer para don Alonso un significado que no se limitaba al de profesión ${ }^{47}$ y función. No en vano había traducido De officiis de Cicerón (ca. 1422) y, por tanto, había de tener presente la honda dimensión ética del étimo latino del vocablo, que precisamente definió de este modo: «los ofiçios tanto quieren dezir commo los actos de las virtudes e convenientes al ome de obrar» ${ }^{48}$. Oficio, por tanto, es actuación conforme a la virtud, una virtud que se contempla en términos de funcionalidad social. Para Cartagena, el oficio de la caballería reposa sobre sólido fundamento ético. Obrar, actuar: en un primer plano figura la dimensión esencialmente activa de la caballería. No es casual que para designar de forma genérica todo el entramado del mundo caballeresco utilice las expresiones «actos de la caballería», «hechos de la caballería» ${ }^{49}$. Especialmente significativa es la primera de ellas, asociada a «oficio»: «actos de la caballería cuyo oficio tienen» (Doctrinal, p. 10).

La caballería constituye, pues, un «oficio", esto es, conforme a la doctrina ciceroniana, una actividad enderezada al desarrollo de una virtud. Para Cartagena, no es un estado, un estamento, sino un oficio que lleva aparejada dignidad, forma

45 La adscripción de la noción de «orden» a grupo social que desempeña una función remonta a Benito de Saint-Maure, quien la introdujo en su Historia de los duques de Normandía (1173-1185) (Georges Duby, Los tres órdenes, pp. 373-376).

46 «... e cualesquier destos caualleros que agora deximos tienen apropiados sus votos, promisiones e juramentos segunt que en la reçepçión de las órdenes, grados e ofiçios a cada vno conviene.» (Qüestión, p. 354).

${ }^{47}$ Se ha sostenido recientemente, en cambio, el carácter «profesional» de la caballería ya desde los inicios de su difusión, en los siglos XII y XIII (Matthew Bennett, «Why Chivalry? Military `Professionalism” in the Twelfth Century: The Origins and Expressions of a Socio-military Ethos», The Chivalric Ethos and the Development of Military Professionalism, ed. D. J. B. Trim, Leiden, Brill, 2003, pp. 41-64).

48 Alonso de Cartagena (trad.) De los ofiçios, Prólogo, apud María Morrás (ed.), Alfonso de Cartagena, p. 208. Debía de tener presente la recepción de la doctrina ciceroniana por parte de san Ambrosio, quien, al formular la definición, propuso la etimología, que carga el acento en la acción: "Officium ab efficiendum dictum putamus, quasi efficium: sed propter decorem sermonis una mutata littera, officium nuncupari.» (De officiis ministrorum, I, viii, ed. J.-P. Migne, PL, t. XVI, París, In via d'Amboise, 1845, col. 31). La exposición de san Ambrosio está presente en el Catholicon, que recoge su etimología: «... officiu(m) q(ua)si efficiu(m) ab efficiendo.» (s. v. officium, fol. 251 roo).

49 Doctrinal, pp. 10, 11. 
superlativa de honor, summus honor, según la definición del Catholicon ${ }^{50}$. No es tanto un ordo, un estamento, cuanto una orden. De este modo, «orden» y «dignidad», referidos a la caballería, pueden considerarse términos intercambiables, sólo que uno enfatiza su especificidad corporativa y el otro su preeminencia social, el honor que se le atribuye ${ }^{51}$.

\section{El ejercicio de las armas.}

El empeño en definir con precisión la naturaleza del oficio caballeresco no lograba evitar cierta ambigüedad. En primer lugar, porque los caballeros no monopolizaban la actividad guerrera. En segundo, porque el término caballero a fines del Medievo pasó a denominar en Castilla a la nobleza media que engrosaría la oligarquía urbana ${ }^{52}$ : de la caballería adoptaba el estilo de vida noble, la dignitas, pero no necesariamente la vocación guerrera. Cartagena manifiesta la conciencia de dicha ambigüedad. Por un lado, al remontarse a los orígenes de la caballería, se refiere al «ofiçio de guerrear» (Qüestión, p. 354), identificando caballero y guerrero; por otro, reconoce la existencia de «combatientes de cauallo» que no son propiamente «caballeros» (Qüestión, p. 355). Pero es más, en el Doctrinal, obra que, por su naturaleza de compilación jurídica sobre la caballería, había de observar una mayor precisión conceptual, se contempla un doble horizonte en la actividad propia de los caballeros: «gobernar la república e la defender e amparar de sus adversarios» ${ }^{53}$. Regimiento y ejercicio de las armas. Don Alonso tiene en mente la realidad social efectiva, la implicación de los caballeros en el gobierno de las ciudades.

Sin embargo, el peso de la tradición del discurso caballeresco castellano, modelado en lo esencial por la exposición que las Partidas de Alfonso X dedican a la caballería ${ }^{54}$, imponía la consideración del oficio caballeresco, el ejercicio de las armas, en el marco de la representación trifuncional de la sociedad y la adscrip-

50 De ahí que se haya afirmado que el ideal caballeresco había cristalizado en torno a la honra (Marie-Claude Gerbet, Las noblezas españolas en la Edad Media. Siglos XI-XV, Madrid, Alianza Editorial, 1997).

51 A este respecto, resulta sumamente ilustrativa la terminología utilizada por el traductor castellano del tratado de Bruni De militia: alterna «dignidad de la caballería» y «orden de la caballería» conforme a los matices señalados (Cfr. De la caballería, p. 113).

52 Marie-Claude Gerbet, Las noblezas, p. 190. Se trata de la culminación de un proceso que arranca del siglo XIII, con la exigencia de requisitos de tipo patrimonial para acceder a los cargos concejiles [Adriana Bo, $\mathrm{M}^{\mathrm{a}}$ del Carmen Carlé, «Cuándo empieza a reservarse a los caballeros el gobierno de las ciudades castellanas», Cuadernos de Historia de España, IV (1946), pp. 144-124].

53 Doctrinal, p. 9. El contexto en que figura tal definición es de especial importancia, pues contempla el ideal del ocio y el negocio propios del caballero.

54 Se ha señalado que la doctrina de la caballería expuesta en las Partidas constituye una suerte de patrón del discurso caballeresco (Gladys I. Lizabe, «El título XXI de la segunda partida de Alfonso X, patrón medieval del tratado de caballería hispánico», Evolución narrativa e ideológica de la literatura caballeresca, ed. M. E. Lacarra, Bilbao, Universidad del País Vasco, 1991, pp. 81-102). Para la situación de las Partidas en la evolución de las ideas sobre la caballería castellana, véase Jesús D. Rodríguez de 
ción, por tanto, de los caballeros al ordo de los «defensores» ${ }^{55}$. Tal es el punto de partida en la reflexión sobre el papel social de los caballeros, centrada, pues, al margen de otras facetas de la realidad, en la actividad guerrera, el "oficio de la caballería». Alonso de Cartagena sistematizó sus ideas acerca de la caballería en la compilación que sobre ella le pidió su amigo el conde de Castro. El orden, la estructura que siguió en la exhaustiva recopilación de fuentes legales revela una concepción bien definida: «establecimientos e doctrinas de la caballería» (Doctrinal, p. 15), tal es la pauta seguida en la selección de los textos reunidos. Pues bien, dicha doctrina viene a articularse en torno a la actividad guerrera, cuya exposición se organiza en tres libros, a los que se añade el último, que versa sobre diversas cuestiones relativas a la nobleza, cuya naturaleza de apéndice ${ }^{56}$, revela la concepción restricta que tenía Cartagena de la caballería.

La índole genuina de las ideas de don Alonso acerca del oficio caballeresco se manifestará de forma explícita en la Qüestión. Aun cuando en esta obra le venía impuesto el tema, aclarar la naturaleza del juramento castrense de los antiguos romanos, decidió obviar la cuestión concreta y desarrollar su propia concepción de la caballería. Tras una exposición acerca del origen y de la exacta delimitación semántica del término miles y su correspondencia con la realidad del presente, enlaza con la cuestión planteada, el juramento, referido ya no a la antigua Roma sino a la actualidad, que le sirve de pretexto para formular las obligaciones esenciales del caballero. El juramento es contemplado como imperativo del arduo compromiso que asume el caballero, el móvil de una actividad que comporta un elevado sacrificio, el riesgo de la propia vida (Qüestión, p. 356).

\section{El oficio de la caballería o los deberes del caballero.}

El empeño de Cartagena por destacar la analogía entre caballeros y letrados y clérigos describe una trayectoria legitimadora de doble sentido: por un lado, los letrados se asimilan a la caballería a través del concepto militia; por otro, los caballeros encuentran en la sacralización un poderoso argumento de legitimación social a través de la analogía con las órdenes religiosas. En efecto, para ponderar la calidad de las «reglas e obseruançia» de los caballeros, se compara con las de

\footnotetext{
Velasco, El debate sobre la caballería en el siglo XV. La tratadística caballeresca castellana en su marco europeo, Salamanca, Junta de Castilla y León, 1996, pp. 19-20.

${ }_{55}$ Cfr. Partida II, tít. XXI, Preámbulo, p. 197. Precisamente, el título tercero del libro I de la compilación reunida por don Alonso, "De los caballeros e de lo que han de fazer», incluye el título citado de las Partidas, que comienza con la consabida representación trifuncional de la sociedad (Doctrinal, p. 20). Para la situación de la recepción alfonsina de dicha representación en el pensamiento hispano véase Vincent Serverat, La pourpre et la glèbe. Rhétorique des états de la société dans l'Espagne médiévale, Grenoble, ELLUG, 1997, pp. 75-78.

56 Para enfatizar su naturaleza de apéndice, desarrolla ampliamente el símil gastronómico referido a la exposición doctrinal: dicho libro vendría a ser una suerte de «postre» al banquete de saberes caballerescos disfrutado (Doctrinal, pp. 251-253). No obstante, los aspectos referidos a la técnica bélica sólo tangencialmente son tratados (Noel Fallows, "Chivalric manuals», p. 69).
} 
cartujos y franciscanos. La caballería deviene así una ascesis de rigor incluso mayor que la que practican los religiosos, pues comporta el sufrimiento derivado de la angustia que produce la proximidad de la muerte (Qüestión, p. 356).

Afrontar la muerte: he aquí la prueba máxima que se exige al caballero. Así, pues, su imperativo radical se sitúa en el marco de la fortaleza de ánimo. Tal es la virtud a que se encaminan los «actos de la caballería». Aun cuando no se cita expresamente, la doctrina ética aristotélica es en este punto invocada ${ }^{57}$. Aristotelismo y Derecho Común, tales son los referentes doctrinales sobre los que Alonso de Cartagena formula su concepción del oficio de la caballería. La guerra es la ocasión en que se ejerce la virtud caballeresca por excelencia, mas no cualquier guerra. Había que establecer cuál era aquella en que el esfuerzo guerrero adquiría naturaleza virtuosa: la doctrina de la guerra justa proporcionaba la respuesta adecuada. Al arrimo de Accursio, destacado glosador, sólo la república, el bien común, exigen el máximo sacrificio (Qüestión, p. 356). Mas don Alonso debió de sentir incompleto tal planteamiento y añadió el desarrollo que «las leyes deste reyno» hicieron de esta doctrina: «defensión de su ley o por seruiçio de su rey e señor natural o por el bien de la tierra e pueblo» 58 .

Defensa de la fe, servicio del rey y bien común. La doctrina sobre la guerra de las Partidas es asumida en su tenor literal. Una rigurosa jerarquía preside la casuística de la legitimación de la guerra: en lugar preeminente la fe, la legitimidad religiosa. A Cartagena no debía de serle ajena la doctrina del Decretum al respecto. Al plantearse Graciano si es lícito que los clérigos empuñen las armas, tras ofrecer en primer lugar argumentos en contra, sostiene que, si bien no pueden hacerlo, en cambio les está permitido exhortar a otros a defender a los oprimidos y luchar contra los enemigos de Dios ${ }^{59}$. Ahora bien, aun cuando reconozca la dimensión sacral del oficio caballeresco, don Alonso reconduce sus consideraciones hacia un planteamiento más bien secularizador ${ }^{60}$. El «bien público» se alza como el norte al que se orientan el esfuerzo, el sacrificio, los trabajos del caballero. Así aparece formulado en la recapitulación de la exposición sobre los dos juramentos aducidos: «jura de non refusar la muerte por el bien público» (Qüestión, p. 359). Se constata el esfuerzo por hacer concordar la doctrina de las Partidas con la de Accursio. Tal vez sintiera Cartagena la necesidad de fundamentar la doctrina caballeresca, en cuestión tan decisiva como la determinación del oficio de los caba-

57 Cfr. Aristóteles, Ética Nicomáquea, 1115a-b, trad. de Julio Pallí Bonet, Madrid, Gredos, 1988 p. 194.

58 Qüestión, p. 356 < Partida II, tít. XXIII, ley II, p. 228. El texto de las Partidas sería incluido en el Doctrinal, p. 59.

59 Decretum, C. 23, q. 8, pars II, col. 1248.

60 Entiéndase por comparación con uno de los textos canónicos de la tratadística hispana, que inicia así su exposición sobre el oficio de la caballería: “Oficio de caballero es mantener y defender la santa fe católica...» (Ramon Llull, Libro de la orden de caballería, trad, L. A. de Cuenca, Madrid, Alianza Editorial, 1996, p. 35). Conviene aclarar al punto que ello no implica, ni mucho menos, que Cartagena obviara la dimensión sacral de la guerra justa. De hecho, en el Doctrinal, viene a legitimarla exclusivamente sobre la defensa y exaltación de la fe (Doctrinal, p. 56). 
lleros, sobre base de la ciencia jurídica, representada por uno de sus cultores más conspicuos. El resultado es una concepción del oficio caballeresco en que prima el compromiso de servicio a la comunidad. Su formulación en los términos de una abstracción transpersonalizadora, el bien común, viene a sugerir la integración de la caballería en la nueva realidad política surgida en el proceso de formación del estado moderno.

Alonso de Cartagena añade otro juramento, que no cuenta con la autoridad de los juristas, sino que viene transmitido por quienes «muchas cosas fermosas de los ritos antiguos en sus libros mesclaron» (Qüestión, p. 357), forma oblicua de referirse, en definitiva, a Frontino. Si el primero se refería al fin al que se encamina el esfuerzo bélico, éste apunta al mantenimiento de la disciplina, a la contención de las pasiones propias del trance bélico en sus dos extremos: cobardía y temeridad o excesivo arrojo ${ }^{61}$. Se va afirmando, de este modo, una orientación decididamente cívica del oficio de la caballería: las virtudes guerreras, antes que contribuir a la glorificación del individuo, se subordinan a la eficacia de la nueva tecnología bélica, en que el orden y la disciplina se erigen en principios de la acción táctica ${ }^{62}$

Al determinar el compromiso máximo del caballero, aquel que le compelía a prestar juramento, el obispo de Burgos se sirve de diversas fuentes, la ciencia jurídica y escolástica, representada por Accursio, y los tratadistas militares más difundidos en el Medievo, Frontino y Vegecio, Derecho Común y militia clásica. No cabe explicar el que silencie a estos últimos por que los supusiera conocidos por Santillana ${ }^{63}$. Se trata de un silencio deliberado que apunta a destacar como aval doctrinal de la vocación cívica de la caballería el Derecho Común.

Y sin embargo, Alonso de Cartagena no pierde nunca de vista la dimensión sacral de la guerra, en que el esfuerzo bélico adquiere calidad virtuosa. En el Doc-

61 «... non fuyr nin partir de la hueste desonestamente por miedo, nin salir adelante la haz o esquadra donde era asignado sin mandado del duque, saluo por recobrar lança que oviese tirado o ferir al enemigo sy de rebato a la sazón le viniese o por defender a su çibdadano si le viese en peligro.» (Qüestión, p. 357). Cartagena ofrece aquí una traducción libre, tendente a la amplificación aclaradora, de Frontino, Stratemegata, IV, 1 (De disciplina): «L. Paulo et C. Varrone consulibus milites primo iure iurando adacti sunt: antea enim sacramento tantummodo a tribunis rogabantur, ceterum ipsi inter se coniurabant se fugae atque formidinis causa non abituros neque ex ordine recessuros nisi teli petendi feriendive hostis aut civis servandi causa." No parece haber seguido la versión castellana que, al parecer, encargara Pedro Fernández de Velasco, conde de Haro y amigo suyo (véase el pasaje en cuestión en María Elvira Roca Barea, Tratado militar de Frontino, p. 255). Para el calado de la lectura de Frontino en las letras castellanas del Medievo véanse las interesantes muestras ofrecidas en Ánge Gómez Moreno, «A propósito de los Deberes y funciones de generales, capitanes y gobernadores de Rodrigo Sánchez de Arévalo», eHumanista, 18 (2011), p. 396 [en línea].

62 Una manifestación más del proceso de formación del estado moderno (José Antonio Maravall, Estado moderno y mentalidad social. Siglos XV a XVII, Madrid, Revista de Occidente, 1972, t. II, pp. 532-536). La disciplina tenía, asimismo, una dimensión ética, referida al autocontrol del caballerocortesano: «They [= términos referidos a la disciplina] signified the kind of elegant self-control that distinguished the moral makeup and outward behavior of the sophisticated courtier.» (Aldo Scaglione, Knights, p. 51).

63 El culto magnate poseyó, en efecto, una versión castellana de la obra de Frontino (María Elvira Roca Barea, Tratado militar, p. 104). 
trinal viene a localizar la esencia de la caballería en la orientación de las virtudes guerreras hacia la máxima meta religiosa: la exaltación de la fe —que se completa a renglón seguido con la ampliación de los límites del reino ${ }^{64}$. Recurre a la retórica de cruzada, a la fórmula de «exaltatio catholicae fidei» 65 . Ahora bien, conviene hacer las siguientes precisiones. En primer lugar, el contexto no dejaba de ser peculiar: Cartagena, en la introducción al libro III, que reúne las «leys que corrigen los bollicios de los reinos» (Doctrinal, p. 191), quiere contraponer al uso perverso de las destrezas bélicas en la vana ostentación de los torneos ${ }^{66}$ la verdadera virtud caballeresca. Para ello, tensa al máximo el imperativo de servicio del caballero, que representa entregado a la causa de la fe, el mayor bien de la comunidad, como indicara en la Qüestión. En segundo, incluso en los momentos de más intensa inspiración religiosa, el obispo de Burgos no deja de tener presente la representación secular de la comunidad política. En efecto, la fórmula en cuestión solía completarse con la alusión a la ampliación de los límites de la Cristiandad; sin embargo, don Alonso refiere el ensanchamiento en esta ocasión al reino, mostrando, por tanto, el carácter político de la conquista territorial.

\section{DE LOS USOS DE LA HISTORIA.}

\section{Una lección decepcionante.}

Al plantearle Santillana al obispo de Burgos una cuestión sobre los usos castrenses de los antiguos romanos, revelaba una curiosidad que cabría calificar de anticuaria. Mas este tipo de conocimiento histórico no carecía de interés práctico, dado que se hacía remontar el origen de la caballería a la antigua Roma ${ }^{67}$. En un momento en que la Antigüedad se revalorizaba como paradigma en todos los órdenes de la vida social, desde la lengua y la literatura hasta incluso la organización política, la cuestión del origen romano de la caballería adquiría especial acuidad.

64 «... la caballería [...] consiste [...] en exalçar [...] la santa fe y ensanchar los términos del reino...» (Qüestión, p. 192).

${ }^{65}$ La considera expresión de la interpretación popular del mensaje de Urbano II Carl Erdmann, Die Entstehung des Kreuzzugsgedankes. Stuttgart, W. Kohlhammer, 1955, p. 321. Véase asimismo Ernst Robert Curtius, «Der Kreuzzugsgedanke und das Altfranzösische Epos», Gesammelte Aufsätze zur romanischen Philologie, Berna-Múnich, Francke Verlag, 1960, pp. 102-104; Jean Flori, «Pur eshalcier sainte crestiënté. Croisade, guerre sainte et guerre juste dans les anciennes chansons de geste françaises», Le Moyen Âge, XCVII.2 (1991), pp. 171-187.

66 Sólo parcial y renuentemente acepta Cartagena la práctica de justas y torneos, encauzándola a través la normativa de la Orden la Banda (Noel Fallows, «Just Say No? Alfonso de Cartagena, the Doctrinal de los caballeros, and Spain's Most Noble Pastime», Studies on Medieval Spanish Literature in Honor of Charles F. Fraker, ed. M. Vaquero, A. Deyermond, Madison, Hispanic Seminary of Medieval Studies, 1995, pp. 129-141).

67 En Castilla, uno de los más entusiastas vindicadores de las raíces romanas de la caballería sería Diego de Valera (Espejo de la verdadera nobleza, pp. 105-106). La materia clásica constituyó uno de los pilares básicos de los valores y la cultura caballeresca (Maurice Keen, La caballería, pp. 145-152). 
Constituía un eficaz recurso legitimador, un argumento destacado para redefinir la función social de la caballería. La línea argumental del opúsculo de Bruni que motiva la pregunta de Santillana se funda en el reconocimiento de la preeminencia de Roma ${ }^{68}$, como si de un axioma se tratara: sin más argumento, ella se erige en la raíz genealógica de la caballería. De ahí el empeño por hacer concordar los usos de los caballeros del fin del Medievo con los de la milicia romana.

No dejaba de ser anacrónico el planteamiento de Bruni, para quien no parece haber solución de continuidad entre la institución creada por el fundador de Roma y la caballería de su tiempo. Alonso de Cartagena, en cambio, revela no sólo una clarividente conciencia histórica, sino un sentido crítico que le permite distanciarse de la reverencia incondicional hacia el legado de la Antigüedad y afirmar decidido la superación de éste que supuso la introducción de la fe cristiana. Así, al tratar de las ceremonias de investidura muestra su escepticismo en una continuidad al respecto en unos términos que suponen un tácito reconocimiento de la superioridad de los modernos sobre los antiguos ${ }^{69}$. "Aquel siglo viejo»: la conciencia de historicidad, de temporalidad, se revela elocuentemente. El cristianismo supone una cesura en el proceso evolutivo que arranca de la Antigüedad. La ley divina añadió a la ley natural por que se guiaban y regían los antiguos un grado de perfección que se había de manifestar en todos los órdenes de la vida social. Cartagena apela al concepto de república cristiana como marco de la vida política y social regida por los principios de la fe cristiana ${ }^{70}$. Éstos regularon tanto el saber como la actividad guerrera. Dada la condición de jurista del obispo de Burgos, es probable que tuviera en mente los esfuerzos de la canonística por regular el ejercicio de la violencia en el marco de la guerra justa ${ }^{71}$.

Así, pues, el cristianismo determinaba la solución de continuidad de la caballería medieval con la romana. Sobre dicha continuidad se fundamentaba el esfuerzo legitimador en que los caballeros más cultivados habían confiado, convencidos de que el conocimiento renovado de la Antigüedad que los humanistas habían aportado podía ofrecer sólidos argumentos para justificar su función social

68 «... nós principalmente acataremos a la çibdad de Roma, así como a princesa de todas las otras e muy bien ordenada.» (De la caballería, p. 111).

69 «Ansí es de pensar que escoger para la cauallería bien lo fazían, mas criarlos e fazer caualleros de la guisa que oy los vedes fazer, bien creo que non lo costunbraron los capitanes antiguos de aquel siglo viejo de que fabló el orador Çiçerón [...] Ca destas cosas después poco a poco entraron quando la xristiana república començo a floresçer e poner todos los actos asý sçientíficos como militares, so reglas justas e ordenanças loables...» (Qüestión, p. 360).

70 Sobre el concepto de «república cristiana» véase Antony Black, Political Thought in Europe, 1250-1450, Cambridge, Cambridge University Press, 1992, p. 42; Antonio Pérez Martín, «La Respublica Christiana medieval: Pontificado, Imperio y reinos», El Estado Español en su dimensión histórica Barcelona, Promociones Publicaciones Universitarias, 1984, pp. 61-128. Para su uso por parte del obispo de Burgos, Luis Fernández Gallardo, «Las ideas políticas de Alonso de Cartagena», Res Publica. Revista de filosofía política, 18 (2007), p. 418.

71 Limitando la crueldad innecesaria y regulando incluso el uso de las armas en función de su excesiva letalidad (James A. Brundage, «Holy War and the Medieval Lawyers», The Crusades, Holy War and Canon Law, Aldershot, Variorum, 1991, X, pp. 113-115). 
y, sobre todo, su status privilegiado. Alonso de Cartagena desbarataba de este modo uno de los principios legitimadores y una de las fuentes de prestigio de la caballería de su tiempo. Al irrefutable argumento de que con el cristianismo la caballería asumió nuevos valores y normas, esas «reglas justas e ordenanças loables» referidas, que la hacían diferente a la romana, añade la intuición personal, basada en una considerable erudición histórica. Con prudente reserva sostiene la inexistencia de las solemnes ceremonias de investidura entre los romanos ${ }^{72}$. Si uno de los fundamentos esenciales de la caballería era la dignidad que se formaliza en tales ceremonias, quedaba invalidada la pretensión de hacerla entroncar con la milicia romana.

Y en este punto, el obispo de Burgos retoma la cuestión de las raíces romanas y le imprime un giro inesperado y sorprendente. Una vez excluido del haber de la herencia romana el ceremonial caballeresco, cabía reconducir la cuestión de los antecedentes clásicos hacia otros aspectos que pudieran tener relación con la caballería. Si el oficio caballeresco se orientaba a la defensa de la república, no podían serle ajenas aquellas cuestiones referidas a la organización militar del reino. Y así, puestos a hablar de antecedentes de la antigua Roma, encuentra más apropiado considerar a los vasallos del rey los propios herederos de los «caualleros que Rómulo en Roma escogió» (Qüestión, p. 361). Los vasallos del rey constituyen una figura jurídica que, referida a la caballería, viene a situarla en el marco de los medios movilizados para la constitución del ejército del reino y, por tanto, incide directamente en la finalidad del oficio caballeresco. Alonso de Cartagena explicaría con su precisión habitual dicha figura:

«... dezimos vasallos del rey a los que dél han cierta cuantía para lanças; [...] pero especialmente nombramos así a aquellos que han dinero dél para lanças, que llamamos "tierra", 73

No necesariamente eran los vasallos del rey caballeros. $Y$ sin embargo, por encima del afán que cunde entre la nobleza ilustrada por prestigiar el oficio cabaIleresco atribuyéndole prosapia clásica, proyección de su fantasía histórica, la clarividencia del obispo de Burgos advierte cuál era el equivalente de la antigua milicia más cercano a la realidad de su tiempo. De la poesía caballeresca que se manifestaba en la solemnidad del ceremonial de investidura se pasaba a la prosa de la realidad institucional; de las palabras solemnes del rito, a los números de los libros contables de la hacienda regia.

La figura de los vasallos del rey constituye una expresión destacada de la peculiaridad del feudalismo hispano, en que los estipendios en metálico o

\footnotetext{
72 «... yo non osaría afirmar que entonçe ouiese dignidad de cauallería con esta solepnidad otorgada commo agora la vsan.» (Qúestión, p. 360).

${ }_{73}$ Doctrinal, p. 252. He aquí, pues, el testimonio que echaba en falta Miguel Ángel Ladero Quesada, Castilla y la conquista del reino de Granada, Granada, Diputación Provincial, 1987, pp. 111-112.
} 
"Soldadas» ${ }^{74}$ concedidos a los vasallos tuvieron una presencia más destacada, sobre todo a partir del siglo XIII ${ }^{75}$. Vasallos del rey no eran propiamente quienes contraían relación vasallática con el monarca ${ }^{76}$. La expresión había cuajado para designar a quienes recibían una renta a cargo de la hacienda regia a cambio de la prestación de servicio de armas. Dicha renta se denominaba «tierra» o «acostamiento", éste último era el tecnicismo hacendístico que figura en los libros de cuentas, y tenía como finalidad financiar el mantenimiento de una «lanza», esto es, la unidad castellana de caballería, que consistía en el equipamiento completo de un hombre de armas (caballo y en ocasiones rocín auxiliar, armamento y personal auxiliar, esto es, dos peones, uno lancero y ballestero el otro). A Alfonso XI se debe la primera regulación sistemática de esta figura, que quedó consignada en el Ordenamiento de $1338^{77}$. Si bien en un principio los vasallos del rey incluían a los ricos hombres, una vez que éstos fueron acumulando señoríos, sobre todo con los dos primeros monarcas Trastámara, su dependencia con respecto a los "sueldos y tierras» fue disminuyendo, con lo que la proporción de pequeños nobles en el conjunto de los vasallos del rey aumentaba. La institución iría decayendo, en virtud de la tendencia a la formación de un ejército permanente, que adquiere especial impulso con los Reyes Católicos ${ }^{78}$.

Así, pues, Alonso de Cartagena echaba por tierra el argumento clave para prestigiar la caballería, en que Santillana depositaba sus expectativas para redefinir la función social del estamento nobiliario: el vínculo genético con la milicia romana, el entronque con una Antigüedad que, merced a los esfuerzos de la erudición humanística, ofrecía sugestivos modelos éticos y cívicos - repárese sin más en las nuevas perspectivas que abría la noción ciceroniana de otium, que tan bien

74 Término que ya en el siglo XV, al menos para Cartagena, era sentido como arcaísmo, como revela la siguiente aclaración: «E desta guisa se usava antiguamente llamar en España vasallo de algún conde o ricoome o señor, el caballero o fijodalgo que dél avía — segund las palabras de entonce- soldada, aunque agora esto non se dize ya tan comúnmente si non en los que han tierra del rey.» (Doctrinal, p. 254).

75 Claudio Sánchez-Albornoz, España, un enigma histórico, Barcelona, Edhasa, 2001, t. II, pp. 775783. Exhaustivo análisis institucional de la soldada vasallática en Hilda Grassotti, Las instituciones feudovasalláticas en León y Castilla, Spoleto, Centro Italiano di Studi sull'Alto Medioevo, 1969, t. II, pp. 723-926, quien la considera de origen islámico (pp. 733-735) y sitúa a partir de Alfonso X el triunfo del régimen de soldadas (pp. 789-806). Véase asimismo la síntesis de Luis G. de Valdeavellano, «Las instituciones feudales en España», El feudalismo hispánico y otros estudios de historia medieval, Barcelona, Ariel, 1981, pp. 124-126.

${ }^{76}$ De título honorífico que no implicaba vasallaje lo califica Marie-Claude Gerbet, Las noblezas, p. 134.

77 Cortes de Burgos (1338), Cortes de los antiguos reinos de León y Castilla, t. I, pp. 450-452. Parece que el término tierra tenía aún el significado original, concesión de bienes raíces: «las soldadas queles mandamos librar en tierras e en dineros», «tan bien tierra çierta commo en dineros» (p. 450).

78 Miguel Ángel Ladero Quesada, «La organización militar de la Corona de Castilla en la Baja Edad Media», Castillos medievales del Reino de León, León, s.n., 1989, pp. 20-22; Miguel Ángel Ladero Quesada, Castilla y la conquista, pp. 111-117 (de «reliquia del pasado» la considera este autor a la altura de 1492, p. 114). Destaca, no obstante, las posibilidades para el fortalecimiento del poder real que tal sistema de reclutamiento tenía Francisco García Fitz, "Las guerras de cada día” en la Castilla del siglo XIV», EDAD MEDIA. Revista de Historia, 8 (2007), p. 155. 
cuadraba al culto magnate. La respuesta del obispo de Burgos a la curiosidad de su amigo Santillana por lo que para éste era cuestión clave, el juramento, elemento esencial del rito de ingreso en la «orden de caballería», tras desarrollar sus ideas sobre los deberes caballerescos, tomando como referencia diversas fórmulas de juramento, viene a ser un jarro de agua fría. Resulta que esos milites a los que se hacía remontar la genealogía de los caballeros medievales eran en realidad los antepasados de los vasallos del rey, cuyo compromiso en la defensa de la «república» se hallaba mediatizado por la percepción de renta a cargo de la hacienda regia. Y el Marqués de Santillana era vasallo del rey. Precisamente por aquellas calendas percibía de la hacienda real 132.000 maravedíes en concepto de tierra, para costear 83 lanzas $^{79}$.

\section{La estatalización de la caballería.}

El mensaje era diáfano. Si Santillana aspiraba a enlazar con la milicia romana, raíz de la dignidad caballeresca, tal parentesco le vendría por su condición de perceptor de rentas a cargo de la hacienda real con que se financia su contribución a la defensa del reino. Dicho de otro modo, si se aceptaba que la milicia romana, aquella instituida por Rómulo cuando escogió los milites —Cartagena se encarga muy bien de puntualizar que éstos eran caballeros-, constituía el origen de la caballería, quienes encarnaban de manera más fiel su naturaleza y esencia en la época de Santillana eran los vasallos del rey, ergo éstos representaban las prístinas virtudes de la caballería. Las puntualizaciones con que el obispo de Burgos aclara el nexo entre éstos y los milites romanos descubren su genuina concepción de la caballería, su ideal. En efecto, dicho vínculo se justifica mediante la apelación a los deberes y derechos de los vasallos del rey:

«... pues con sus personas, cauallos e armas deuen ser prestos a guerrear por la república quando por el príncipe les fuere mandado, e biuen de las rentas comunes que a los reyes paga su regno.» (Qüestión, pp. 361-362)

De nuevo la república es la instancia que impele al ejercicio de las armas. Cartagena se esfuerza por adoptar un vocabulario político en que la abstracción transpersonalizadora se tensa al máximo, mediante el uso del cultismo cuyas resonancias clásicas facilitaba la vinculación con la Antigüedad. Ahora bien, el servicio a la comunidad política se halla mediatizado por la autoridad real, que se erige, de este modo, en el principio rector de la caballería. El término «príncipe» opera asimismo en esa dirección hacia la abstracción de las nociones políticas: apunta a destacar al titular de la instancia de poder soberano. El oficio de las armas es ejercido no tanto en virtud de un compromiso contraído ritualmente cuanto

79 Según los datos hacendísticos de 1447 consignados en el libro de asentamientos de rentas de Juan II publicado por Luis Suárez Fernández, «Un libro de asientos de Juan II», Hispania, XVII (1957), pp. 323-368 (datos sobre Santillana en p. 333). 
por mor de una contraprestación económica, la que satisface esa comunidad, el reino que ha de ser defendido por el caballero, mediante los tributos, las «rentas comunes", pagados a la Hacienda regia.

Alonso de Cartagena aprovechaba la consabida invocación del paradigma de la Antigüedad para formular su propia concepción del oficio caballeresco. En un primer plano, una inequívoca vocación cívica, que se sitúa en el marco institucional de la monarquía. El oficio del caballero se subordina al poder real. Al rey corresponde convocar a los caballeros para luchar por la república. Más que en el énfasis puesto en la dimensión cívica del oficio caballeresco, la novedad de la concepción de la caballería que desarrolla don Alonso radicaba en la contraprestación económica. El caballero pasaba a ser un servidor del estado; la caballería, un organismo más en el aparato estatal. De este modo, la función social de la caballería se integraba en las estructuras institucionales que surgen de la configuración del estado moderno: unas fuerzas armadas financiadas a cargo de la Hacienda regia. Sin embargo, a pesar del esfuerzo por formular una concepción de la caballería integrada en las estructuras estatales, la realidad de las relaciones de tipo feudal había de imponerse inexorablemente. Tras las consideraciones fuertemente impregnadas de sentido institucional, la aclaración del uso del término «tierra» para designar estipendios en metálico revela la inexcusable dimensión feudal de la relación vasallática de la figura en cuestión ${ }^{80}$.

El obispo de Burgos estaba proponiendo una estatalización de la caballería, desplazando el foco de interés desde la dignidad del caballero a la vocación de servicio, que pierde ese carácter personal que presentaba la apelación a la defensa de viudas y huérfanos para asumir un fuerte sentido institucional. De hecho, no deja de mostrar su crítica al afán de honor que animaba a quienes aspiraban a la dignidad caballeresca, pero se desentendían de la función guerrera. Un acusado pragmatismo inspira el discurso de don Alonso sobre la caballería. Que no se trataba de meras lucubraciones doctrinales en abstracto se pone claramente de manifiesto en las precisiones que hace sobre las rentas percibidas por los vasallos del rey, elocuente testimonio de que se planteaba la viabilidad económica de esta forma de mantenimiento de fuerzas armadas, pues no se le oculta que dichas rentas se había devaluado considerablemente como consecuencia de las devaluaciones monetarias ${ }^{81}$.

La propuesta que formula el obispo de Burgos se fundamentaba en el Derecho Común y la razón. Las ideas que desarrolla en la Qüestión coinciden con las que ya expuso, cuando estudiaba en Salamanca, en forma de disputatio de quolibet.

80 «... e non syn cabsa se llaman vasallos, e el dinero que les dan tierra se dize, dando a entender que es vasallaje a manera de feudo...» (Qüestión, p. 362).

81 «... ca avnque paresca pequeña la quantía que a vn vasallo se da, pero quando este vso se començó para razonable mantenimiento bastara si mudança de las monedas non le dieran gran baxa...» (Qüestión, p. 362). Sobre la situación monetaria aludida, Angus Mackay, Money, Prices and Politics in Fifteenth Century Castile, Londres, Royal Historical Society, 1981, pp. 63-65. Para las actitudes de la nobleza ante la política monetaria, pp. 99-101. Véase asimismo, Miguel Ángel Ladero Quesada, «La política monetaria en la Corona de Castilla (1369-1497)», En la España Medieval, 11 (1988), pp. 97-100. 
La tesis viene a ser similar. Entonces defendía que los vasallos del rey pudieran gozar de los privilegios caballerescos; a la altura de 1444, que éstos representaban del modo más genuino la milicia romana, raíz de la caballería. El erudito jurista es plenamente consciente de que el Derecho Común carece de efectividad legal. Por ello, apela a la «prouidençia real», para que lo que se propone en el ámbito académico, en «las escolásticas disçeptaçiones», puede ponerse en práctica (Qüestión, p. 362). Así, está exhortando al rey a que haga real esta nueva concepción de la caballería, cuya legitimidad se hace derivar de los sólidos fundamentos racionales del Derecho Común, que entran en contradicción con «algunas leyes del regno e la costumbre» (Qüestión, p. 362).

\section{NOBLEZA Y CABALLERÍA.}

Al traer a colación la cuestión del estatuto privilegiado de los caballeros a propósito de la evocación de la actividad académica salmantina (Qüestión, p. 362), el obispo de Burgos situaba la reflexión sobre la caballería en el marco de sus relaciones con la nobleza. Para don Alonso, nobleza y caballería constituyen dos ámbitos que se solapan, que comparten un amplio espacio común, pero no llegan a coincidir plenamente. Esa estrecha relación, pero, a su vez, deslinde, entre nobleza y caballería se pone de manifiesto en la justificación del corpus legal recopilado en el Doctrina/ ${ }^{82}$. Cartagena no hacía sino reflejar la realidad social ${ }^{83}$ : no había más que reparar en ese grupo considerable de caballeros pecheros, cuya investidura no suponía el acceso a la nobleza. De hecho sus pretensiones al privilegio fiscal, a la exención tributaria, fueron firmemente denegadas por la realeza, ante la presión de las Cortes, alertadas por la disminución del número de contribuyentes debido a la proliferación de tales investiduras ${ }^{84}$.

Las ideas del prelado burgalés acerca de las relaciones entre caballería y nobleza vienen a oscilar entre la aceptación del punto de vista nobiliario tradicional, que enfatiza la noción de linaje y sangre como criterio identitario, y la propuesta de una concepción alternativa que hacía radicar la nobleza en la virtud, cuya recompensa, el honor o dignitas, administraba el rey. Efectivamente, por un lado, parece

82 «Entre las leyes deste reino se contienen algunas que pertenescen a fechos de caballería, e otras aunque non fablan de caballería pero son actos que se suelen fazer por los caballeros e fijosdalgo.» (Doctrinal, p. 15). Poco más atrás, al referirse las fuentes jurídicas de la doctrina caballeresca, se hace alusión a las leyes «que pertenesce saber a los fijosfalgo e caballeros.» (p. 14).

${ }^{83}$ Desde una amplia perspectiva histórica han sido expuestas con claridad meridiana dichas relaciones por Jean Flori, La caballería, Madrid, Alianza Editorial, 2001, pp. 109-116.

${ }^{84}$ Desde Toledo se expidió el 20 de diciembre de 1422 una pragmática para que los pecheros que se armaran caballeros no dejasen de pechar por ello (BNE, ms. 13104, fols. 101-104). Véase al respecto Nelly Raquel Porro, «La investidura de pecheros en los días de Juan II», Cuadernos de Historia de España, LXXIII (1991), pp. 147-171. De ahí que la equiparación entre caballería y nobleza propuesta por Adeline Rucquoi, «Être noble en Espagne aux XIVe-XV siècles», Nobilitas. Funktion und Repräsentation des Adels in Alteuropa, ed. O. G. Oexle, W. Paravicini, Gotinga, Vandenhoeck \& Ruprecht, 1997, pp. 273-298, no resulte del todo exacta desde un punto de vista estrictamente institucional. 
asumir la identidad entre caballería y nobleza, esto es, limitar el acceso a la condición de caballero a los nobles o hidalgos: incluye -imperativos, empero, de antólogo- la ley alfonsina que establece la condición noble del caballero ${ }^{85}$, a la vez que reconoce que la doctrina caballeresca resulta de interés asimismo para los nobles o «fijosdalgo» (Doctrinal, p. 14). Mas por otro, el alto ideal de la caballería formulado dejaba entrever la insuficiencia del linaje, la clara sangre, como argumento legitimador de la nobleza. La caballería propuesta constituye una alta exigencia ética que obliga a una suerte de ascesis, análoga a la de los religiosos. Para el adecuado ejercicio del oficio caballeresco no basta la calidad de la sangre ni el arrojo o valentía, dos de los valores axiales de la nobleza tradicional ${ }^{86}$.

El empeño contemporizador que anima las reflexiones de don Alonso, reacio a impugnar explícitamente los valores tradicionales, da lugar a una cierta ambigüedad, en virtud de la cual se da por supuesta la calidad noble del caballero a la vez que se propone vincular la dignidad caballeresca no tanto a la condición de hidalgo, cuanto al desempeño del oficio, esto es, la defensa de la república. Cartagena, de este modo, establece una significativa distinción entre «actos de la caballería» y «actos pertenescientes a caballeros» (Doctrinal, p. 252). Si se tiene en cuenta que las leyes reunidas en el libro IV, en cuyo prólogo figuran ambas expresiones, se refieren casi en su totalidad al derecho nobiliario, habrá que colegir que tal distingo vendría a reflejar el compromiso entre el ideal y la realidad. El término abstracto «caballería» polarizaría la aspiración al ideal, en tanto que el concreto «caballero» remitiría a la realidad social, en la que el punto de vista nobiliario monopolizaba la institución de la caballería.

Para el obispo de Burgos la comunidad más radical entre nobleza y caballería residiría en el privilegio. Y es que éste era el signo más evidente de la condición noble. Si el privilegio se justificaba en razón de la función que la nobleza desempeñaba en la sociedad, a la que regía y defendía con las armas ${ }^{87}$, las consideraciones que desarrolla Cartagena acerca del estatuto privilegiado de los caballeros venían a situarse, a su vez, en el debate sobre la nobleza. Que la cuestión le atraía vivamente se pone de manifiesto en el hecho de que siendo aún estudiante de Leyes sostuvo una disputatio sobre dicha cuestión y, transcurrido casi medio siglo, recordaba los argumentos entonces alegados (Qüestión, p. 362). Don Alonso se refiere a los «priuillejios militares» (Qüestión, p. 362), esto es, a los derivados de la investidura caballeresca. Éstos cubrían una amplia gama de aspectos, desde los gestuales y más propiamente honoríficos, hasta los que tenían una mayor sustantividad, los jurídicos y económicos ${ }^{88}$. La idea que tenía de dichos privilegios se revela claramente en el Doctrinal, en la medida en que duplica la normativa

85 Doctrinal, p. 23-24 < Partida II, tít. XXI, ley 2, 3, t. II, pp. 198-200.

86 «No se engañe alguno cuidando que en la claridad de la sangre y en el denuedo solo del coraçón consiste todo el loor de los caballeros...» (Doctrinal, p. 10).

$87 \mathrm{M}^{\mathrm{a}}$ Concepción Quintanilla Raso, «La nobleza», pp. 66, 68.

88 Nelly R. Porro Girardi, La investidura de armas en Castilla. Del rey Sabio a los Católicos, Valladolid, Junta de Castilla y León, 1998, pp. 187-270. 
relativa a éstos. En efecto, el título tercero del libro I recoge íntegro el título XXI de la Partida II, cuyas leyes XXIII y XXIV regulan las «honras» que han de gozar los caballeros $^{89}$. A su vez, el título noveno del libro IV recoge normativa diversa de los reyes Alfonso XI y Juan II sobre privilegios que se otorgan a los caballeros ${ }^{90}$. Especialmente significativo es este último, pues supone la selección expresa, con mayor grado de consciencia que el acarreo del título XXI completo de la Partida II, de aquella normativa relativa al privilegio caballeresco, de manera que deja traslucir su concepción al respecto. Las disposiciones legales recogidas se refieren a la protección del patrimonio del caballero, especialmente su equipamiento guerrero, a la exención fiscal, a la esencial garantía procesal consistente en no poder ser sometido a tormento $\mathrm{y}$, finalmente, a la dispensa de la normativa limitadora del lujo.

Así, pues, Cartagena sitúa en un primer plano los privilegios que protegen el equipamiento militar, con el que el caballero ha de ejercer su oficio. Más que el aspecto honorífico del privilegio, le interesaba garantizar la función esencial que le había sido encomendada al caballero. Este interés pone de manifiesto el concepto que el obispo de Burgos tiene del privilegio. En la Qüestión vincula el disfrute del privilegio al «oficio» desempeñado por el caballero, esto es, al imperativo de «yr a las guerras» (Qüestión, p. 362). Y es que, desde el riguroso planteamiento ético que está en la base del pensamiento político y social de Alonso de Cartagena, el privilegio, en tanto que reconocimiento de honra u honor, había de ser el premio de la virtud, conforme a la doctrina aristotélica ${ }^{91}$. La virtud del caballero no es otra que el ejercicio de las armas, puestas al servicio de la república, esto es, el cabal desempeño de su oficio.

El planteamiento del obispo de Burgos se distanciaba, pues, del punto de vista tradicional que vinculaba el goce del privilegio a la calidad de la sangre. Las Partidas, a pesar del esfuerzo por situar la caballería bajo el control del poder real, consagrarían dicha vinculación ${ }^{92}$. Sin embargo, Cartagena no es una voz discordante en el escenario ideológico castellano de la época. Su concepción del oficio caballeresco subordinado al bien común y, por tanto, superador de privilegios estamentales, no es disímil del empeño por erradicar, por el extremo opuesto de la marginación social, la exclusión de los judíos del servicio militar sobre la base de

89 Doctrinal, pp. $42-43$ < Partida II, tít. XXI, ley XXIV, pp. 217-218.

90 Doctrinal, pp. 299-302.

91 Que ya en su primera obra original expuso don Alonso con claridad meridiana: «Nam honor nichil aliud est q(uam) reu(er)encia exhibita in signum virtutis, quod Aristot(elis) in io Ethic(orum) probat...» (Alonso de Cartagena, Memoriale virtutum, BNE, ms. 9178, fol. 8 vo). Cfr. Aristóteles, Ética Nicomáquea, 1123b, p. 220.

92 «Honrados deben ser mucho los caballeros, et esto por tres razones; la una por nobleza de su linaje; la otra por su bondat; la tercera por la pro que dellos viene...» (Partida II, tít. XXI, ley XXIII, p. 216). Tal doctrina sería recogida en la ordenanza de Juan II sobre privilegios relativos a la indumentaria incluida en el Doctrinal (p. 302). Cartagena, al destacar la tercera razón, vendría a alterar una jerarquía de valores presidida por la preeminencia del linaje. 
que la defensa de la comunidad también les atañía ${ }^{93}$. De este modo, la asunción de una noción de la comunidad política que iba más de allá de conceptos transpersonalizadores tales como reino y corona, que aún connotaban un vínculo personal con el monarca, permitía un grado de abstracción en la formulación de las obligaciones de los miembros de ella que tendía a diluir las diferencias estamentales. República ${ }^{94}$, bien común constituyen los referentes a que se orienta el imperativo del caballero, que, de este modo, adquiere una acusada dimensión cívica, desmarcándose de una fidelidad de carácter personal propia de los vínculos feudales.

Alonso de Cartagena en modo alguno cuestionaba - al menos explícitamente-la legitimidad del estamento nobiliario basada en el linaje, pero, al menos en lo que respecta a la caballería, ofrecía sólidos argumentos para avalar la opinión alternativa que cuestionaba la preeminencia de la sangre como elemento definidor de la nobleza. Precisamente la caballería que él propone constituye una forma de excelencia superior a la mera pertenencia a un linaje noble, conforma una aristocracia fundamentada en una nueva concepción del ejercicio de las armas, en la que se contempla un nuevo horizonte ético y técnico.

\section{LA NUEVA DOCTRINA CABALLERESCA.}

\section{El peso de la cultura letrada: lectura y estudio.}

La alta exigencia del oficio caballeresco imponía una capacitación que requería una cuidada instrucción. Ya en las primeras formulaciones del ideal caballeresco la enseñanza del caballero ocupa un lugar nuclear: es lo que se ha denominado "fábula pedagógica», mediante la cual se instruye al caballero novel, proporcionando la ocasión idónea para la formulación teórica ${ }^{95}$. En el siglo XV, las hondas inquietudes intelectuales que cunden entre un significativo sector de la nobleza castellana tenían que repercutir en el horizonte teórico y doctrinal de la caballería. El interés por las formas de cultura letrada había de enriquecer considerablemente la doctrina caballeresca. Frente a la enseñanza de carácter esencialmente oral en que se plasmaba la «fábula pedagógica», testimonio, a su vez,

93 Se trata del interesantísimo caso de la obligación de incluir a los judíos de la ciudad de Murcia que tuvieran el nivel de renta requerido entre los caballeros cuantiosos. Esto ocurría en 1445. El jurista Alonso Díaz de Montalvo adujo la seguridad militar de la ciudad para tal medida (Juan Torres Fontes, «La incorporación a la caballería de los judíos murcianos en el siglo XV» [Folleto], Murcia, Academia Alfonso X el Sabio, 1966, pp. 6-7).

94 No es casual que una de las obras de doctrina política más difundidas en el Bajo Medievo comience con una exposición del concepto de república (Juan de Gales, Communiloquium, I, 1, fol. 4 ro a).

95 Jesús D. Rodríguez-Velasco, Ciudadanía, soberanía monárquica y caballería. Poética del orden de caballería, Madrid, Akal, 2009, pp. 16-17. 
de las formas de pensamiento tradicional ${ }^{96}$, el oficio de la caballería se ofrece ahora en el Cuatrocientos como un saber predominantemente libresco ${ }^{97}$.El análisis que hace don Alonso de las fuentes de los valores caballerescos no puede ser más aclarador al respecto.

En primer lugar declara la naturaleza escrita del saber relativo a la caballería ${ }^{98}$. Al vincular la lectura a la vocación por las armas — sumamente elocuente es la expresión "despertar los corazones»- se estaba privilegiando esta vía de acceso a los valores y el saber propios del oficio caballeresco. Tácitamente se estaba, asimismo, sugiriendo que no sólo la sangre, el linaje, sino el estudio hacen al caballero. Tres tipos de escritos distingue el prelado burgalés: "doctrina de sabidores", ejemplos de la historia ${ }^{99}$ y leyes (Doctrinal, p. 11). Es de notar la fuerte impronta clásica que presenta el repertorio ofrecido de los escritos relativos a la caballería. Los «sabidores» no son otros que los «filósofos» y los «oradores griegos y latinos»; entre las fuentes históricas, se mencionan expresamente las "corónicas, así generales como romanas» (Doctrinal, p. 11). Cartagena se revela así decidido valedor de la militia clásica, que presenta como ejemplo de la caballería de su tiempo. El acceso al conocimiento de las doctrinas de esos oradores griegos y latinos tenía que ser necesariamente a través de la escritura, que exigía una lectura individual y silenciosa, no como la que recomendaba Alfonso el Sabio a los caballeros, que aún conserva una vigorosa oralidad ${ }^{100}$. Muy diferente a la disposición del oyente es la del lector. Frente a la pasividad de quien asiste a una actuación (lectura oral, espectáculo juglaresco) el lector asume un papel activo en el

96 En que el saber posee un carácter fijo y estático y constituye una sabiduría o sapiencia que se toma donde se encuentra [José Antonio Maravall, «La concepción del saber en una sociedad tradicional», Estudios de historia del pensamiento español. Edad Media (Serie primera), Madrid, Ediciones Cultura Hispánica, 1983 (3ª ed.), pp. 211-215].

${ }_{97}$ Aun cuando perdure vigorosa la oralidad entre las formas de cultura nobiliaria. En lo que respecta a los valores caballerescos, la semblanza de Rodrigo Manrique que trazó Hernando del Pulgar ilustra elocuentemente la vigencia de la transmisión oral del saber de la caballería, tanto de modo teórico, como práctico: «Su plática con ellos era la manera del defender e del ofender el enemigo...»; «Fablava muy bien y deleitávase en recontar los casos que le acaescían en las guerras." (Claros varones de Castilla, ed. R. B. Tate, Madrid, Taurus, 1985, pp. 124, 126). Por el contrario, la valoración de la vista, el sentido implicado en la lectura, como medio de conocimiento, constituye un signo de modernidad que se ha localizado en el siglo XV (José Antonio Maravall, «La concepción del saber», p. 241).

98 «E como sean muchas cosas escritas, así en los tiempos antiguos como en los más cercanos años, para despertar los corazones en los fechos de la caballería...» (Doctrinal, p. 11).

99 Destaca la ejemplaridad militar de la cronística bajomedieval Ángel Gómez Moreno, «La militia clásica y la caballería medieval: las lecturas de re militari entre Medievo y Renacimiento", Evphrosyne, XXIII (1995), pp. 89-90).

100 «... et por eso acostumbraban los caballeros quando comien que les leyesen las hestorias de los grandes fechos de armas que los otros fecieran...» (Partida II, tít. XXI, ley XX, p. 213). Elocuente expresión de esa oralidad que se inscribe en la concepción tradicional del saber es el recurso, sustitutorio de la lectura de crónicas e historias, a "caballeros buenos et ancianos» (figura tópica de la «fábula caballeresca») y a «juglares» (p. 213). La lectura oral es una práctica que se prolonga en España hasta bien entrado el Siglo de Oro (Margit Frenk, Entre la voz y el silencio, Alcalá de Henares, Centro de Estudios Cervantinos, 1997, pp. 21-38). Se ha aducido la figura de don Quijote como ejemplo conspicuo de la forma moderna de lectura solitaria (Ricardo Senabre, «Alonso Quijano, lector», $A B C$ 22-4-1997, p. 3). 
diálogo que constituye la lectura. El espectador se torna estudioso: de modo harto elocuente, Cartagena empareja los verbos «estudiar» y «leer» en el elogio de los afanes estudiosos de su amigo Santillana (Qüestión, p. 350). El nuevo caballero no sólo se ha de ejercitar con las armas al aire libre, sino que debe recogerse en su gabinete para estudiar en los libros una doctrina caballeresca cuyos contenidos se han ampliado considerablemente. El nuevo caballero deviene intelectual.

Ese saber ávidamente buscado a través del estudio era efectivamente un saber científico. Ciertamente, constituía un principio asumido por quienes reflexionaban sobre la institución caballeresca, especialmente los miembros más conscientes de la nobleza ilustrada, la necesidad de la unión de ciencia y caballería ${ }^{101}$. Cartagena participa de esta estimación del saber caballeresco, que denomina «dotrina estudiosa e guiadora de la re militar» (Qüestión, p. 349), atribuyendo calidad de ciencia a los saberes cultivados en los espacios de ocio y que motivan la cuestión que plantea Santillana ${ }^{102}$. Por otra parte, en su dilecto Séneca hallaba confirmada esta convicción: en el florilegio de dichos de Vegecio atribuido a Séneca figura uno que reza lo siguiente: «Saber pelear quiere osadia, el qual saber se llama sçiençia de la republica» ${ }^{103}$. Y sin embargo, precisamente en el momento en que la reflexión sobre la legitimidad de la dedicación del caballero al estudio presenta una mayor densidad, parece mostrar cierta renuencia a reconocer el estatuto científico de ese saber relativo a caballería. En el prólogo del Doctrinal diríase que se sugiere una oposición entre las «altas ciencias» en que «se ocuparon los grandes varones» (p. 10) y aquellas que constituyen el imperativo estudioso de los caballeros, relativas a «los actos de la caballería» (p. 10), esto es, como si las últimas carecieran del marchamo científico. Ahora bien, dado que en el horizonte de lecturas estudiosas que contempla don Alonso, la ciencia ocupaba un lugar innegable, como es el caso de los "diversos e notables libros, así de filósofos como de oradores griegos e latinos» (Doctrinal, p. 11), habrá que atribuir tal renuencia a que tuviera asimismo en mente obras de carácter esencialmente técnico, cuyos contenidos constituirían más bien un ars antes que scientia, esto es, un saber cuya certeza se basa en la experiencia, a diferencia de la ciencia, que la hace

101 Fernán Pérez de Guzmán, amigo de Cartagena, ofrece quizás el testimonio castellano más acabado al respecto: «Sciencia e caualleria / [...] esta noble compañia / es muy grande de juntar; / pero junta nin ha par, / nin precio su grant valia.» (Coplas de vicios y virtudes, copla 325, ed. R. Foulché-Delbosc, Cancionero Castellano del siglo XV, Madrid, Casa Editorial Bailly-Bailliére, 1912, t. I, p. 67). Probablemente, Pérez de Guzmán se hace eco aquí de uno de los paradigmas de la biografía caballeresca: «Yceulz .Il. pillers, sanz faille, sont Chevalerie et Science qui moult bien se couviennent ensemble...» (Le Livre des Fais du Bon Messire Jehan Le Maingre, dit Bouciquaut, I, 1, ed. D. Lalande, París-Ginebra, Droz, 1985, pp. 6-7).

102 «... ansí el animoso deseo del estudioso varón todavía falla alguna ora oportuna en que en la silua de la sçiençia tome onesto deleyte...» (Qüestión, p. 352).

103 Tomás González Rolán, Pilar Saquero Suárez-Somonte, «El Epitoma rei militaris de Flavio Vegecio traducido al castellano en el siglo XV. Edición de los "Dichos de Séneca en el acto de la caballería” de Alonso de Cartagena», Miscelánea Medieval Murciana, XIV (1987-1988), p. 129. 
reposar en los fundamentos causales ${ }^{104}$, que se aprehenden por medio de la especulación racional. Bajo la rúbrica de «doctrina de sabidores», la primera categoría de escritos sobre los actos de caballería, podrían incluirse tales obras: además de las de los sabios filósofos y oradores, posiblemente tendría en mente el obispo de Burgos obras sobre estrategia, justas, heráldica ${ }^{105}$, en fin, todo ese saber práctico que no podía ignorar un caballero cabal.

\section{Honestum otium: la garantía del orden estamental.}

Aun cuando tan encarecidamente pondera la necesidad del estudio para el adecuado ejercicio del oficio caballeresco, Alonso de Cartagena no logra superar plenamente la conciencia de incompatibilidad entre ejercicio de las armas y estudio, expresión de los valores de la caballería tradicional, que no dejaba de gravitar sobre cultos magnates como Santillana. Efectivamente, la carta peticionaria que dirige a su amigo Cartagena se plantea la posible recriminación por parte de éste sobre la pertinencia del requerimiento, dada la grave situación política de enton$\operatorname{ces}^{106}$. El hecho de que admita la posibilidad de tal reproche en el docto prelado burgalés pone de manifiesto cierta inseguridad en la licitud de la dedicación del caballero responsable de sus obligaciones cívicas a la lectura y el estudio. Diríase que el culto magnate se presenta con humildad, con cierto temor de que fuese tachado de irresponsable. De hecho, la pesimista visión que muestra de la situación política

104 Conforme al concepto de ciencia formulado por Santo Tomás: «Cognitio vero rerum humanarum vocatur scientia, quasi communi nomine importante certitudinem iudicii appropriato ad iudicium quod fit per causas secundas. Et ideo, sic accipiendo scientiae nomen, ponitur donum distinctum a dono sapientiae. Unde donum scientiae est solum circa res humanas, vel circa res creatas.» (Summa Theologiae, II-2, q. 9, a. 2). Precisiones sobre el concepto de ciencia dentro del panorama intelectual castellano de la época en Jeremy Lawrance, «Las lecturas científicas de los castellanos en la Baja Edad Media», Atalaya, 2 (1991), pp. 142-146, que se plantea inteligentemente la "ubicación bibliológica de la sçiençia» (p. 142). Por su parte, uno de los autores castellanos más representativos de los valores caballerescos, se refiere al «arte de la caballería» (Gutierre Díez de Games, El Victorial. Crónica de Don Pero Niño, conde de Buelna, ed. J. de Mata Carriazo, Madrid, Espasa-Calpe, 1940, p. 44), ¿consciente de las implicaciones epistemológicas del término? Más decisivo al respecto es el testimonio de un erudito letrado, discípulo además de Cartagena, que, al tratar de la caballería en su visión de la sociedad, le dedica un capítulo sobre «la arte de cauallería. y del campo. y del exercicio de las armas» [Rodrigo Sánchez de Arévalo, Espejo de la vida humana, apud John Richard Law (ed.), El «Spejo dela vida humana» de Rodrigo Sánchez de Arévalo (1404-1470): Estudio y edición crítica, Míchigan, Ann Arbor, 1980, p. 226]. Para la dualidad scientia-ars en el contexto de los saberes del siglo XV véase Peter Burke, A Social History of Knowledge. From Gutemberg to Diderot, Cambridge, Polity Press, 2000, p. 83.

105 Analizadas por Ángel Gómez Moreno, «La militia clásica», pp. 95-97. Constituyen lo que se ha denominado "specialized and predominantly secular erudition connected with chivalry», de la que los heraldos, clers des armes, serían sus cultores más representativos (Maurice Keen, “Chivalry, heralds, and history", The Writing of History in the Middle Ages. Essays Presented to Richard William Southern, ed. R. H. C. Davis, J. M. Wallace, Oxford, Clarendon Press, 1981, pp. 408-409).

106 Santillana, Questión, p. 348. Es posible que Santillana haga referencia a la reacción subsiguiente al golpe de Rámaga, que cuajaría en la guerra que estalló en la primavera de 1444, en la que la nobleza castellana, capitaneada por don Álvaro de Luna, se alzó contra la hegemonía de los Infantes de Aragón. Análisis de esta coyuntura política en Luis Suárez Fernández, Nobleza y Monarquía. Puntos de vista sobre la historia política castellana del siglo XV, Valladolid, Universidad de Valladolid, 1975, pp. 157-160. 
de Castilla, que parangona con ejemplos clásicos de crueldad, codicia y disensiones civiles, concluye con una suerte de reproche a sí mismo y al estamento caballeresco en su conjunto por su incapacidad para resolver los graves problemas que pesaban sobre la sociedad castellana ${ }^{107}$.

Ahora bien, el refinado magnate ofrecía asimismo la clave para resolver el conflicto que le surgía al caballero entre obligaciones cívicas y vocación estudiosa. Al plantearse la posible recriminación de dejación de sus obligaciones estamentales, afirma resueltamente que él no ha olvidado sus deberes cívicos. Y en este punto introduce la solución al conflicto mediante la idea de ocio: «fago deste trabajo [= dedicación al estudio] reposo de los otros» ${ }^{108}$. La dedicación a las letras como descanso, alivio de las fatigas y ansiedades que procuran el ejercicio de las armas constituye un motivo ya presente en don Juan Manuel, quien en una de esas preciosas confidencias personales consideraba la lectura - repárese: lectura oral- como alivio del insomnio que le causaban los continuos afanes y cuidados en que vivía ${ }^{109}$. Ahora bien, tales consideraciones se inscriben en el marco de la concepción de la literatura como recreación ${ }^{110}$. Aunque no se contempla un espacio de tiempo correspondiente a ese recreo, Santillana, empero, avanza un paso en la dirección que conduce a la noción de honestum otium en la medida en que ese «reposo» consiste en un trabajo, esto es, en una actividad productiva que supone esfuerzo; ya no se trata de asistir pasivamente a la lectura oral, sino de desarrollar el esfuerzo intelectual que requiere el estudio y que, en última instancia, redundará en beneficio de la comunidad.

Mas lo que en Santillana se presentaba más bien como intuición adquiere en Alonso de Cartagena un desarrollo sistemático, que cuaja en el concepto de honestum otium, de prosapia romana. Su más acabada elaboración figura en la Epistula dirigida al conde de Haro sobre los estudios literarios, que cabe fechar hacia $14422^{111}$. Don Alonso asume la noción ciceroniana de otium: retiro de las ocupaciones de la vida pública, que podía ser honestum o inhonestum, según se

107 «Ansí que denegados nos deuen ser cualesquier galardones que fueron otorgados e prometidos a los virtuosos, pugnadores e deseadores del bien de la patria e propulsadores e debelladores de los enemigos de aquélla e defensores de la república.» (Santillana, Questión, p. 349). Cartagena compartía análoga desazón acerca de la situación política castellana (Qüestión, p. 351).

108 Santillana, Questión, p. 348.

109 «... el cuidado es una de las cosas que más faze al omne perder el dormir, et esto acaece a mí tantas vezes que me embarga mucho a la salud del cuerpo; et por ende cada que só en algún cuidado, fago que me lean algunos libros o algunas estorias por sacar aquel cuidado del coraçón.» (Don Juan Manuel, Libro del caballero et del escudero, p. 375).

110 Los autores escolásticos recurrían al concepto de «recreación» para justificar la literatura desde una perspectiva psicológica y ética (Glending Olson, Literature as Recreation in the Later Middle Ages, Cornell, Cornell University Press, 1986, pp. 90-127). No es de extrañar que entre las diversiones del Medievo se incluya la lectura dentro de los «plaisirs de l'esprit» (Jean Verdon, S'amuser au Moyen Âge, París, Tallandier, 2003, pp. 259-282).

111 Formulado expresamente en Alonso de Cartagena, Epistula directa ad Petrum Fernandi de Velasco, apud Jeremy N. H. Lawrance (ed.), Un tratado de Alonso de Cartagena sobre la educación y los estudios literarios, Bellaterra, Universidad Autónoma de Barcelona, 1979, p. 36. 
ocupe en el estudio o en placeres meramente corporales ${ }^{112}$. En la Qüestión figura una variante en la enunciación de la idea: «onesto deleyte» (p. 352). Allí plantea don Alonso de modo análogo el contraste entre la dedicación de Santillana al estudio y la entrega a los deleites sensuales (p. 350). En primer lugar, pondera que su «deleyte e descanso» consiste en «estudiar e leer e avn escreuir» (Qüestión, p. 350). A continuación precisa que quienes se maravillan de tal hecho son precisamente quienes se mantienen apegados a los placeres corporales más elementales, lo que constituye una apelación evidente a la identificación que hacía Cicerón entre voluptas e inhonestum otium ${ }^{113}$. La implícita recriminación de la puntualización anterior revela cierto cariz polémico en las consideraciones de don Alonso. Si el hallazgo del espacio adecuado para la dedicación al estudio permitía eliminar los escrúpulos que podían surgir con relación al adecuado cumplimiento de las obligaciones estamentales del caballero — de hecho, el obispo de Burgos puntualiza que tan honestos menesteres no ocupan el tiempo que exige el servicio a la república (Qüestión, p. 352) —, quedaba expedita la vía para la vindicación del menester intelectual frente a su reprobación sobre la base de que era impropio del oficio de las armas. Y no sólo la defensa, sino la crítica de la opinión adversa. Santillana buscaba ávido en la respuesta de su amigo el obispo de Burgos la confirmación de la licitud de sus ocupaciones librescas. Cartagena, en cambio, no sólo la avala, sino que la esgrime para lanzar una tácita crítica contra quienes dedicaban sus ocios a placeres corporales elementales.

Una mayor trascendencia presenta el desarrollo que hace don Alonso del tema en el Doctrinal.

\section{La prudencia: redefinición de las virtudes caballerescas.}

La incorporación de la dimensión intelectual, de la faceta estudiosa a la figura del caballero había de modificar necesariamente el sistema de valores y virtudes caballerescas ${ }^{114}$. Alonso de Cartagena revela una aguda conciencia de tales reper-

112 J. P. V. D. Balsdon, «Auctoritas», p. 47; Ch. Wirszubski, «Cicero's Cum Dignitate Otium», Journal of Roman Studies, 44, 1954, pp. 1-13.

113 J. P. V. D. Balsdon, «Auctoritas», p. 47.

${ }_{114}$ Con el término sistema se hace referencia simplemente al conjunto de virtudes propias de la institución de la caballería, enunciadas y expuestas por la literatura caballeresca, tanto la tratadística como la lírica cortesana o la novela artúrica. Se obvia, por tanto, la cuestión de si hubo un «sistema ético (Tugendsystem) caballeresco", que con Curtius adquiere intenso cariz polémico al refutar sistemáticamente la tesis formulada al respecto por Ehrismann (1919) [Ernst Robert Curtius, Literatura europea, t. II, pp. 724-749, de que conviene retener lo siguiente: «El atractivo peculiar del ethos caballeresco consiste justamente en esa fluctuación entre muchos ideales, en parte emparentados y en parte contradictorios.» (p. 747)]. Por su parte, un reconocido estudioso actual de la caballería retoma el concepto ritterliches Tugendsystem (Franco Cardini, «El guerrero y el caballero», El hombre medieval, ed. J. Le Goff, Madrid, Alianza Editorial, 1991, p. 92). A su vez, aborda el análisis de las virtudes caballerescas Joachim Bumke, Höfische Kultur. Literatur und Gesellschaft im hohen Mittelalter, Múnich, Deutscher Taschenbuch Verlag, 2005, pp. 416-430, pero, dado que su objeto son, en realidad, las höfische Tugenden, se limita sólo a las fuentes literarias, básicamente poéticas. 
cusiones y aprovechó así la ocasión que le ofrecía la justificación de la composición del Doctrinal para plantear una firme redefinición de las tales virtudes, que no obvia un cierto cariz polémico en la medida en que los nuevos valores se confrontan con los que representarían la posición contraria al cultivo de las letras. Si la dedicación al estudio viene a ser el complemento de los trabajos y afanes caballerescos, la prudencia lo será de la fortaleza, virtud axial de la caballería ${ }^{115}$.

Ciertamente, la propuesta de una virtud o cualidad moderadora de la valentía o fortaleza de ánimo remonta a las más tempranas reflexiones sobre el ideal guerrero. El tópico sapientia-fortitudo, cuyo desarrollo en la tradición occidental estudiara Curtius, es buena prueba de ello. Ya en los poemas homéricos se constata que «el verdadero héroe posee además la sabiduría», además del vigor corporal $^{116}$. Se ha observado la tendencia a encarnar ambas virtudes en sendos personajes, cuyo paradigma representa la pareja Roldán y Oliveros ${ }^{117}$. Ahora bien, la consideración de la prudencia, concebida conforme a la doctrina ética aristotélica, como virtud propia de la milicia remonta a Santo Tomás de Aquino, que distingue cuatro tipos de prudencia orientada al gobierno de la multitud: militaris, oeconomica, regnativa y politica ${ }^{118}$. Mas su sistematización dentro de una rigurosa reflexión sobre el estamento caballeresco corresponde a su discípulo Egidio Romano. Éste parte del análisis del Aquinate, que le sirve de marco para hacer de la prudencia la virtud nuclear del oficio militar ${ }^{119}$. Ahora bien, mientras que para Santo Tomás la prudencia viene a identificarse con la aptitud para el mando y dirección de efectivos militares, su discípulo le confiere un contenido más específicamente marcial, ligado al ejercicio y finalidad de la actividad bélica ${ }^{120}$. Por otra parte, dentro de la tradición hispana, las Partidas, al enumerar las virtudes o «bondades» de los caballeros, situaban en preeminente lugar la cordura, que se identifica con la pru-

115 El quiasmo subraya dicha complementariedad: «Ca el esfuerço discreto e la esforçada discreción son de loar en los caballeros...» (Doctrinal, p. 9). Cartagena consideraba prudencia y discreción como sinónimos: «E la disposicio(n) (et) habito d(e)l entendimie(n)to q(ue) esto bie(n) gouierna es la virtud intellectual q(ue) se llama prudencia, q(ue) comu(n)mente llamamos discrecio(n).» (Oracional, Murcia, Lope de la Roca, 1487, sig. b 6 roํ).

116 Ernst Robert Curtius, Literatura europea, t. I, 247.

117 Franco Cardini, Guerra di primavera. Studi sulla cavalleria e la tradizione cavelleresca, Florencia, Le Lettere, 1992, p. 88, quien propone un sugestiva interpretación en clave de los arquetipos de Jung.

118 «Est autem quaedam multitudo adunata ad aliquod speciale negotium, sicut exercitus congregatur ad pugnandum, cuius regitiva est prudentia militaris. Quaedam vero multitudo est adunata ad totam vitam, sicut multitudo unius domus vel familiae, cuius regitiva est prudentia oeconomica; et multitudo unius civitatis vel regni, cuius quidem directiva est in principe regnativa, in subditis autem politica simpliciter dicta.» (Santo Tomás de Aquino, Summa Theologiae, II-2, q. 48).

119 Sistematiza las clases de prudencia, distinguiendo cinco tipos: «Sciendum igitur militare $(\mathrm{m})$ ese quandam prudentiam siue quandam speciem prudentiae. Possumus autem quantu(m) ad praese $(n)$ s spectat distinguere quinq(ue) species prudentiae, uidelicet prude(n)tiam singulare $(m)$, yconomicam, regnatiua $(m)$, polliticam siue ciuile $(m)$ \& militarem.» (De regimine principum, III, 3, 1, sig. u ii ํo).

120 «Militaris ergo est quaedam species prudentiae per quam superantur hostes \& prohibentes bonum ciuile \& commune.» (De regimine principum, III, 3, 1, sig. u iii ro). Ya el hecho de que se alegue la autoridad de Vegecio (III, 3, 1, sig. u ii voํ) es indicativo al respecto. Para la aportación de Egidio Romano a la doctrina caballeresca véase Aldo Scaglione, Knights, pp. 83-86. 
dencia aristotélica ${ }^{121}$. Alonso de Cartagena se acoge, por tanto, a una venerable tradición de pensamiento político que erige la prudencia en virtud fundamental de la caballería.

Diríase que asume por igual los planteamientos de las dos grandes autoridades mencionadas. En efecto, en consonancia con Santo Tomás, la justificación de la dedicación al estudio por parte de los caballeros con que se abre el prólogo del Doctrinal se sitúa en el marco de una concepción del oficio caballeresco en que prima la dimensión rectora ${ }^{122}$. Mas el obispo de Burgos extiende el ámbito de la prudencia a que se refería Santo Tomás más allá de la dirección estrictamente militar, ya que alude expresamente al «regimiento» en tiempo de paz, de manera que antes que a la figura del caballero, parece apuntar al estamento nobiliario en su conjunto. La prudencia quedaba entonces inevitablemente asociada al ejercicio del poder. Las virtudes del caballero se refieren no sólo a la actividad bélica, sino que incluyen su participación en la sociedad política —habrá que pensar no tanto en la que tenía por cauce las instituciones en que desempeñaba un relevante papel, las Cortes y el Consejo Real, sino en el ejercicio de sus atribuciones en el marco del poder señorial. Al cultivo de este tipo de prudencia corresponden las lecturas científicas - las propias de ese «trabaio de ciencia» al que se dedicaban los «famosos cavalleros» (Doctrinal, p. 9). Por otra parte, a continuación, Cartagena, en la línea establecida por Egidio Romano, sitúa la prudencia o discreción en un horizonte propiamente marcial, en la medida en que se erige en guía de la valentía ${ }^{123}$. Este modo de prudencia se cultiva a través del estudio de «lo que pertenesce a los actos de la caballería» (Doctrinal, p. 10).

En su Memoriale virtutum, el obispo de Burgos había trazado una precisa exposición de esta virtud conforme a la doctrina aristotélica ${ }^{124}$, otorgándole un papel central en el sistema ético, al hacer de ella el fundamento de las virtudes morales (Memoriale, fol. 7 roํ). Así, la subordinación de la fortaleza de ánimo, término aristotélico del «denuedo» caballeresco, a la prudencia obedecía a arraigadas convicciones doctrinales.

La centralidad de la prudencia en el horizonte de las virtudes caballerescas que había proclamado Egidio Romano es asumida por el obispo de Burgos, que, de este modo, propone una jerarquía en las virtudes de la caballería que modifica

121 «... la cordura les [= defensores] fará que lo [= defensa de la comunidad] sepan facer á su pro et sin su daño...» (Partida II, tít. XXI, ley IV, t. II, p. 200). Cfr. Aristóteles, Ética Nicomáquea, 1140a, p. 273.

122 «Los famosos caballeros [...] acostumbraban interponer algún trabaio de ciencia por que más onestamente supiesen regir a sí e a aquellos cuyo regimiento les pertenescía ansí en fechos de paz como de guerra...» (Doctrinal, p. 9).

123 «... ca la discreción debe mandar al denuedo e non el denuedo a la discreción.» (Doctrinal, p. 11).

124 Reproduce fielmente la definición que da Aristóteles: «PRUDENCIA est ille habitus q(ui) reddit homine $(m)$ pote $(n)$ tem bene consiliari circa propria bona et vtilia, non in aliquo negocio particulari, set vniversaliter circa om(n)ia que sunt bona et vtilia ad hoc ut tota vita humana sit bona et recta.» (Memoriale, fol. 5 rํํ). Cfr. Aristóteles, Ética Nicomáquea, 1140a, p. 273. Completa, sin embargo, la exposición doctrina con referencias a la autoridad de san Agustín y san Gregorio (fol. 7). 
la concepción tradicional. "Esfuerzo», «denuedo» son los términos que han de subordinarse a la «discreción» o prudencia (Doctrinal, 9, 11). Con ellos don Alonso designaba la valentía, la fortaleza de ánimo según la terminología aristotélica. Se trata del arrojo, el coraje que se manifiesta en el combate, esa prouesse que se ha considerado como "qualcosa di più vicino alla furia incontrollata dell' «eroedàimon» ${ }^{125}$. El valor más preciado por los caballeros, el honor, se fundamenta en la valentía, de manera que el deshonor resulta ligado especialmente a su opuesto, la cobardía. En la medida en que el honor posee una dimensión no sólo individual, sino colectiva, asociada al linaje, impelía a aumentarlo mediante gestas, proezas que proporcionaban fama y gloria ${ }^{126}$. Pues bien, a ese imperativo de excelencia guerrera que conllevaba el desprecio del riesgo y del peligro por mor de la honra se le imponen unos límites, definidos por la prudencia, que va a subordinar el honor a la eficacia bélica. De este modo, la prudencia viene a identificarse con la disciplina, el sometimiento del arrojo guerrero a un criterio racional. En la medida en que la función del caballero es la defensa de la comunidad, de la república, sus virtudes habían de estar orientadas a la consecución de este fin. La dimensión cívica de la caballería, netamente establecida ya por Egidio Romano al vincular su función al bien común, obligaba a desplazar el foco de interés de la demostración del valor individual al sometimiento a la disciplina, en que se cifra la eficacia militar. La prouesse cedía así la preeminencia a la prudencia.

La Qüestión proporciona un ilustrativo testimonio de esa relación entre estudio, prudencia y disciplina. Efectivamente, el juramento tomado de Frontino (Qüestión, p. 357) limitaba la pulsión bélica de los guerreros impacientes de entrar en combate, sometiéndolos a la disciplina, al mando del superior. Se trataba, por tanto, de un principio extraído de un autor de la Antigüedad, por tanto, de instrucción teórica sobre el arte de la guerra sólo accesible a través de la lectura, del estudio. Dicho principio impele a someter el impulso surgido del arrojo bélico a la disciplina y la obediencia. Constituye la aplicación práctica de la máxima acuñada por don Alonso, según la cual «la discreción debe mandar al denuedo». Se aduce la batalla de Aljubarrota (1385), en que murió el abuelo de Santillana, para mostrar las funestas consecuencias del «denuedo» desnortado, carente de la guía de la prudencia (Qüestión, p. 358).

La prelación de la prudencia no representa sólo un reajuste en la jerarquía de las virtudes caballerescas, introduce, además, sustanciales transformaciones cualitativas en el sistema de valores de la caballería, que se sitúan en esa misma línea estatalizadora observada a propósito de la consideración de los vasallos del rey como expresión de la milicia original. El ethos caballeresco limita la dimensión individual, volcada en la búsqueda de la gloria a través de la proeza en que se

125 Franco Cardini, Guerra di primavera, p. 87. En ella se manifestaría la exaltación viril que subyace en el ethos caballeresco [A. Barbero, «Guerra, nobiltà, onore fra Tre e Quattrocento», Studi Storici, XXVII (1986), p. 186].

126 Jean Flori, Chevaliers, p. 263. 
exhibe la valentía, al situarse la finalidad y razón de ser de la caballería no tanto en una suerte de ascesis y perfección del caballero, cuanto en el bien común. La defensa de la república exigía eficacia en la gestión de sus efectivos bélicos antes que proezas individuales. La creciente complejidad y la progresiva tecnificación de la guerra imponían la subordinación de la iniciativa individual a las necesidades de una nueva estrategia basada en la disciplina y la coordinación de los diferentes componentes del ejército.

Cabría plantearse si las transformaciones en las ideas se tradujeron en cambios en la praxis, esto es, considerar el calado social de la reflexión teórica. Ciertamente, el planteamiento de Cartagena se inscribe en una tradición de pensamiento que deriva de Santo Tomás de Aquino y Egidio Romano ${ }^{127}$. Su aportación original se limitaría a la explícita subordinación de la fortaleza de ánimo a la prudencia, en el carácter moderador que le atribuye, reorientando la pulsión belígera a su encuadre en una estrategia presidida por el principio de disciplina. El obispo de Burgos desplazaría el foco de interés de la prudencia desde las cualidades de mando, tal y como estableciera Santo Tomás, al dominio de sí, a la autocontención del caballero. Desde esta perspectiva concreta, al menos en el plano de las estimaciones y los valores, se observa una actitud receptiva a esa forma de integración de la prudencia en las virtudes caballerescas. No es casual que sea Fernán Pérez de Guzmán, amigo de Cartagena a cuya amable instigación se deben obras fundamentales como el Duodenarium o el Oracional, quien asuma plenamente sus planteamientos. En su galería de biografías de nobles y prelados castellanos la cordura o discreción sigue en la prelación de las virtudes a la fortaleza y a la liberalidad. Es de notar que asocia esfuerzo y sabiduría al ponderar las cualidades de Pedro Suárez de Quiñones, en una línea análoga a la de Cartagena ${ }^{128}$. Sin embargo, en lo que respecta a la efectividad práctica de esa exhortación a limitar la pulsión belígera, ¿estaban efectivamente dispuestos nobles y caballeros a modificar los hábitos bélicos adquiridos a través de una educación eminentemente práctica, basada en el adiestramiento en equitación, manejo de armas, caza y justas ${ }^{129}$ El caso de Santillana pone elocuentemente de manifiesto las contradicciones generadas por el desajuste entre teoría y práctica, entre lo predicado y lo realizado. Su actuación en la batalla de Torote (1441) revela cómo a pesar de estar imbuido de numerosas lecturas que exhortaban a la prudencia «caballeril», siguió

127 Ilustra las vicisitudes de la estimación de la prudencia «caballeril» Jesús D. Rodríguez Velasco, «De prudentia», pp. 123-130.

128 Fernán Pérez de Guzmán, Generaciones y semblanzas, ed. J. Domínguez Bordona, Madrid, Espasa-Calpe, 1924, p. 79. Véase el análisis al respecto de Luis Fernández Gallardo, «Disidencia política y nuevos valores nobiliarios en Generaciones y semblanzas», En la España Medieval, 25 (2002), pp. 292-293. Ciertamente, no figuran ni la Qüestión ni el Doctrinal en el inventario de su biblioteca, mas ello no implica que Pérez de Guzmán no hubiese leído o tenido conocimiento de ambas obras [véase Mercedes Vaquero, Cultura nobiliaria y biblioteca de Fernán Pérez de Guzmán, Ciudad Real, Oretania, 2003, pp. 144-147 (inventario) y 24-44 (análisis)].

129 Isabel Beceiro Pita, «Educación y cultura en la nobleza (siglos XIII-XV)», Anuario de Estudios Medievales, 21 (1991), pp. 584-585; Isabel Beceiro Pita, «La educación: un derecho y un deber de cortesano», Libros, lectores y bibliotecas en la España medieval, Murcia, Nausícaä, 2007, pp. 146-151. 
los dictados del honor caballeresco, exponiéndose de modo «imprudente» ${ }^{130}$. Sobre las enseñanzas del saber libresco se imponían las exigencias del honor nobiliario, caballeresco: el temor a perder la honra asentada en el valor guerrero hacían inoperantes las normas aprendidas en los libros. Y es que el peso de tales valores era tal que invalidaba el esfuerzo por racionalizar el ethos caballeresco, ajustándolo a los imperativos de eficacia bélica que exigían disciplina. Las batallas campales eran concebidas como una suerte de torneo cortesano ${ }^{131}$. De este modo, el impacto de las nuevas ideas sobre la caballería asimiladas a través de las lecturas estudiosas parece limitarse al ámbito estrictamente ideológico de las estimaciones, no llegando a afectar a esa praxis que se proponía modificar. Incluso los nobles más entusiastas de los nuevos valores, llegado el momento, se veían inexorablemente impelidos a seguir las conductas impuestas por el ethos tradicional, en que la prouesse prevalecía sobre la sagesse.

\section{CONCLUSIÓN. ¿UN HUMANISMO CABALLERESCO?}

A lo largo de su dilatada producción escrita Alonso de Cartagena reflexionó reiteradamente sobre la caballería o cuestiones a ella atingentes. Dicha reflexión, sin llegar a presentar un desarrollo sistemático, adquiere una mayor densidad en dos obras cuyo tema es la caballería, la Qüestión y el Doctrinal, compuestas ambas en fechas próximas, entre 1444 y 1448, y, por tanto, en plena madurez intelectual del autor. Al ser obras de encargo, la perspectiva, el enfoque le venía dictado a don Alonso por la naturaleza de la petición o ruego del comitente. Sin embargo, a pesar de lo parcial del tema abordado, el rigor que preside el quehacer intelectual del obispo de Burgos determina un desarrollo detallado que va más allá de la petición concreta, de manera que ofrecen un perfil completo de sus ideas sobre la caballería.

Una aguda conciencia de las obligaciones estamentales y un profundo sentido ético: tal viene a ser el marco en que se inscriben las ideas de Cartagena sobre la caballería. Ambas premisas adquieren pleno sentido en la intensa inspiración cívica que anima su pensamiento político y social. El bien común constituye el fin a que se encaminan las funciones que han de desempeñar los diferentes estamentos sociales, los «estados". El orden social se fundamenta en el equilibrio armónico que preside la contribución de las distintas funciones al bien común. De ahí que el intrusismo, el arrogarse funciones que no le corresponden -o se creen no

130 Conforme al análisis de Fernando Castillo Cáceres, «La caballería y la idea de la guerra en el siglo XV: el Marqués de Santillana y la batalla de Torote», Estudios sobre cultura, guerra y política en la Corona de Castilla (siglos XIV-XVII), Madrid, CSIC, 2007, pp. 79-110, especialmente 81-82.

131 Como revela el análisis de la batalla de Olmedo (1445) [Fernando Castillo Cáceres, «¿Guerra o torneo?: la batalla de Olmedo, modelo de enfrentamiento caballeresco», En la España Medieval, 32 (2009), pp. 139-166]. 
corresponder - a un estamento es contemplado como un peligro para el orden social $^{132}$.

No es casual que una de las primeras consideraciones sobre la caballería figure en un encendido y retórico elogio de la profesión académica, que le sirve de exordio al discurso sobre la ley Gallus, pronunciado en Aviñón (1434). Caballeros y letrados aparecen unidos compartiendo un mismo afán. Ciertamente, éste no es otro que la realización de largos viajes para aprender de los más destacados cultores del oficio y alcanzar así la excelencia. Mas la tácita apelación a la imagen organicista $^{133}$ apuntaba a destacar que las funciones sociales de ambos confluían en un mismo fin: la defensa de la república. Cartagena invocaba la caballería para afirmar su identidad estamental como letrado. Así, pues, desde la perspectiva del letrado y del clérigo contemplaba la función social de la caballería: la preservación de la comunidad mediante las armas. La defensa de la república ya no es concebida como función que monopolicen los guerreros, por cuanto no sólo las armas la conservan ${ }^{134}$.

El obispo de Burgos sitúa el desempeño del oficio caballeresco en un preciso encuadre institucional. Si la milicia romana se había erigido en paradigma de la caballería, en la medida en que representaba sus prístinas raíces, quienes mejor encarnaban el ideal caballeresco habían de ser su equivalente de entonces, que para Cartagena eran los vasallos del rey. De este modo, la caballería, en una propuesta ideal que se asimilaría a la figura de los vasallos del rey, venía a formar parte del entramado institucional del reino. $Y$ es que para quien fuera uno de los más eficaces ideólogos de la monarquía autocrática la caballería había de estar subordinada al poder real.

Dicha subordinación iba a adoptar la forma de una relación contractual en función de la cual al servicio de armas prestado por el caballero le correspondía una retribución con cargo a la hacienda real. Como heredera de la soldada vasallática, la renta percibida por los vasallos del rey llevaba asimismo asociada las connotaciones propias del vínculo feudal originario. Sin embargo, lo que destaca

${ }_{132}$ Cartagena se revela sumamente sensible a esta cuestión, especialmente, con relación al estudio, función propia de los letrados, alertando ante las consecuencias de la dedicación universal al cultivo de las letras: «Non que diga que todos sean letrados, ca la governaçión de la cosa pública non lo padesçe...» (De senetute, p. 155). No hay que perder de vista que en tal planteamiento se manifiesta la voz del letrado celoso del monopolio de su función (Luis Fernández Gallardo, Alonso de Cartagena, pp. 366-367).

${ }_{133}$ Analiza la imagen organicista en Cartagena a través del Memoriale, De senetute, De los ofiçios, De la clemençia, De preeminentia, la Qüestión y el Defensorium, Francisco Castilla Urbano, «La función de la metáfora organicista en la obra de Alonso de Cartagena», INGENIUM. Revista de historia del pensamiento moderno, 5 (2011), pp. 77-103 (mas se incluye bajo la categoría de imagen organicista lo que es simple reconocimiento de funciones correspondientes a los diferentes estamentos sociales sin referencia explícita a órganos corporales).

${ }^{134}$ Conforme al clarividente planteamiento de Juan de Salisbury: «Neque enim reipublicae militant soli illi, qui galeis thoracibusque muniti, in hostes exercent gladios, aut tela quaelibet, sed et patroni causarum,qui gloriosae vocis confisi munimine, lapsa erigunt fatigata reparant...» (Polycraticus, col. 589). 
Cartagena es el fundamento económico del oficio militar, lo cual obedece a arraigadas convicciones, pues ya en su primera obra original aparece análogo planteamiento ${ }^{135}$. El oficio caballeresco devenía así función pública. La caballería se integraba así en las estructuras del naciente estado moderno. El servicio al bien común, que presentaba tenía en las formulaciones originarias de la ideología caballeresca un componente ético orientado a la perfección del individuo ${ }^{136}$, adquiere en el pensamiento de Cartagena una dimensión cívica que se encuadra en los aparatos del estado.

Concebida la caballería como oficio dependiente de la corona, don Alonso propone para ella unos valores que, frente al individualismo del ethos tradicional, centrado en la exaltación del valor, destacaban su dimensión cívica. Así, procede a una redefinición de las virtudes caballerescas. Acogiéndose a la tradición que derivaba de Egidio Romano - y que contaba, asimismo, con el aval de las Partidas- sitúa en lugar preeminente la prudencia, más le confiere un contenido en cierta medida novedoso. Consciente de que la virtud propia del caballero era la fortaleza de ánimo, le asignará a la prudencia un papel moderador, para evitar los excesos de un «esfuerzo» que tenía sólo por norte la exaltación individual e integrarlo en una estrategia militar basada en la disciplina. La prudencia caballeresca se adquiere a través del estudio, esto es, de una formación libresca. El caballero, además de ejercitarse al aire libre en las destrezas propias del arte bélico, ha de cultivar mediante el estudio, recogido en su gabinete, el saber que le dotará de prudencia. Se trata de un saber científico que incluye lecturas que forman parte del programa humanístico. Para Cartagena, Santillana encarnaría paradigmáticamente esta integración de la vocación estudiosa en la figura del caballero.

¿Cabe aplicar a una tal propuesta de caballería el concepto de humanismo caballeresco? Ciertamente, la expresión resulta atractiva y ha cautivado a los estudiosos que han tratado de esta faceta de la caballería. Ahora bien, hay que tener en cuenta que en su formulación original dicho concepto presentaba unos contenidos muy diferentes a lo que han venido a asumirse como una suerte de communis opinio ${ }^{137}$. Su acuñador quería integrar dentro del humanismo toda una corriente de la literatura y la cultura italianas, «quel tipo di cultura e di civiltà che si

135 «Frecuencius enim sunt uocandi milites ad defendend(am) rem publicam q(uam) agricole, quia illi stipendiis rei publice ectiam tempore pacis viuu(n)t.» (Memoriale, fol. 13 roํ). Esa aguda sensibilidad hacia e fundamento económico de la maquinaria militar diríase anticipa las reflexiones al respecto de Maquiavelo, tal y como las desarrolla en el «Discurso sobre la provisión del dinero» (apud Maquiavelo, Antología, ed. M A. Granada, Ediciones Barcelona, Península, 2002, pp. 189-196).

${ }^{36}$ Como puede observarse, una vez más, en Juan de Salisbury, para quien la publica utilitas constituiría el reverso de los vicios del guerrero: «Sed quo fine [arriesgar la vida y el alma]? An ut furori, vanitati, avaritiae serviant, an proprie voluntati? Nequaquam. Sed ut faciant in eis judicium conscriptum, in quo quisque non tam suum, quam Dei, angelorum, et hominum sequatur ex aequitate et publica utilitate arbitrium.» (Polycraticus, col. 600).

137 Lo asume como ideal que encarna paradigmáticamente Santillana Fernando Castillo Cáceres, «La caballería», p. 102. De modo análogo, Carlos Moreno Hernández, Retórica y humanismo: El Triunfo del Marqués de Santillana (1458). Estudio y edición, Valencia, Universitat de València, Textos Lemir, 2008, pp. 89-90. 
esprime nei romanzi cavallereschi dai francoveneti al Tasso „138. Por otra parte, si se parte de la prudencia, de su revalorización como componente del ethos caballeresco, en buena lógica habría que hablar más bien de «escolasticismo caballeresco", teniendo en cuenta sus raíces tomistas. No obstante, es un dato incontestable la índole humanística de la nueva sensibilidad que se manifiesta en la propuesta del prelado burgalés -y, asimismo, en los afanes estudiosos de su amigo Santillana-, sólo que ello no justifica el reconocimiento de una variante específica del humanismo, pues, de la misma manera habría que fragmentarlo en múltiples variantes (pictórico, musical, científico...) Más ajustado a la realidad histórica sería apelar simplemente a la utilización de elementos del humanismo, la aplicación de los studia humanitatis, de la retórica humanística, representados por los oradores e historiadores antiguos, a cuya lectura exhortaba don Alonso para cultivar la prudencia, en la caballería.

Integración en las estructuras institucionales del estado moderno e integración de la retórica humanística: tales son los términos en que cabe cifrar la aportación de Alonso de Cartagena al ideal caballeresco.

\footnotetext{
${ }_{138}$ Ruggero M. Ruggieri, L'umanesimo caballeresco italiano da Dante al Pulci, Roma, Edizioni dell'Ateneo, 1962, p. 10. De ahí que una buena parte de la literatura propiamente humanística no sea tenida en cuenta -ni siquiera De militia de Bruni es citada. No es este el lugar para valorar la idoneidad de este concepto: repárese simplemente en que para hacer pasar por humanística tal literatura habría que estirar de tal modo el concepto de humanismo, que perdería sustantividad para caracterizar un movimiento clave de la cultura europea. Hay que notar, asimismo, que dicho concepto ya había sido formulado, pero sin que llegara a cuajar en una exposición sistemática. Al hilo del análisis metafísico de la aventura caballeresca, se introduce para dar razón de la superación de la tensión que amenazaba el ideal cortés: «Wir werden noch sehen, wie sich das Unbewältigte der neuen und das Fremdgewordene der alten in eine 'andere' Welt umsetzen, die sich bedrohlich um jene ideale höfische Sphäre legt, in der aus der Spannung selbst, im Versuch ihrer Überwindung, ein ritterlicher Humanismus entsteht.» [Erich Köhler, Ideal und Wirklichkeit in der höfischen Epik, Tubinga, Max Niemeyer Verlag, $1970^{2}$, p. 89 (la primera edición apareció en 1956)]. Humanismo viene a ser una genérica adscripción al ideal de humanitas, una concepción del hombre que surge del poder generado en la tensión que subyace en el concepto de aventura: «... eine positive Kraft erwächst, deren Ergebnis die neue Konzeption des sich entwickelnden, perfektionierenden und in dieser Tätigkeit die Gemeinschaft konstituirenden Menschen ist.» (p. 89)
} 